\title{
Averting biodiversity collapse in tropical forest protected areas
}

\author{
A list of the authors and their affiliations appears at the end of the paper.
}

The rapid disruption of tropical forests probably imperils global biodiversity more than any other contemporary phenomenon ${ }^{1-3}$. With deforestation advancing quickly, protected areas are increasingly becoming final refuges for threatened species and natural ecosystem processes. However, many protected areas in the tropics are themselves vulnerable to human encroachment and other environmental stresses $^{4-9}$. As pressures mount, it is vital to know whether existing reserves can sustain their biodiversity. A critical constraint in addressing this question has been that data describing a broad array of biodiversity groups have been unavailable for a sufficiently large and representative sample of reserves. Here we present a uniquely comprehensive data set on changes over the past 20 to 30 years in 31 functional groups of species and 21 potential drivers of environmental change, for 60 protected areas stratified across the world's major tropical regions. Our analysis reveals great variation in reserve 'health': about half of all reserves have been effective or performed passably, but the rest are experiencing an erosion of biodiversity that is often alarmingly widespread taxonomically and functionally. Habitat disruption, hunting and forest-product exploitation were the strongest predictors of declining reserve health. Crucially, environmental changes immediately outside reserves seemed nearly as important as those inside in determining their ecological fate, with changes inside reserves strongly mirroring those occurring around them. These findings suggest that tropical protected areas are often intimately linked ecologically to their surrounding habitats, and that a failure to stem broad-scale loss and degradation of such habitats could sharply increase the likelihood of serious biodiversity declines.

Tropical forests are the biologically richest ecosystems on Earth ${ }^{1-3}$. Growing concerns about the impacts of anthropogenic pressures on tropical biodiversity and natural ecosystem services have led to increases in the number and extent of protected areas across the tropics ${ }^{10}$. However, much remains unknown about the likelihood of biodiversity persisting in such protected areas. Remote-sensing technologies offer a bird's-eye view of tropical forests and provide many important insights ${ }^{6,11-13}$, but are largely unable to discern crucial onthe-ground changes in forest biodiversity and ecological functioning ${ }^{14}$.

To appraise both the ecological integrity and threats for tropical protected areas on a global scale, we conducted a systematic and uniquely comprehensive assessment of long-term changes within 60 protected areas stratified across the world's major tropical forest regions (Supplementary Fig. 1). To our knowledge, no other existing data set includes such a wide range of biodiversity and threat indicators for such a large and representative network of tropical reserves. Our study was motivated by three broad issues: whether tropical reserves will function as 'arks' for biodiversity and natural ecosystem processes; whether observed changes are mainly concordant or idiosyncratic among different protected areas; and what the principal predictors of reserve success or failure are, in terms of their intrinsic characteristics and drivers of change.

To conduct our study we amassed expert knowledge from 262 detailed interviews, focusing on veteran field biologists and environmental scientists who averaged nearly 2 decades of experience

(mean \pm s.d., $19.1 \pm 9.6$ years) at each protected area. Each interviewed researcher completed a detailed 10-page questionnaire, augmented by a telephone or face-to-face interview (see Supplementary Information). The questionnaires focused on longer-term (approximately 2030 -year) changes in the abundance of 31 animal and plant guilds (trophically or functionally similar groups of organisms), which collectively have diverse and fundamental roles in forest ecosystems (Table 1). We also recorded data on 21 potential drivers of environmental change both inside each reserve and within a 3-km-wide buffer zone immediately surrounding it (Table 1).

Our sample of protected areas spans 36 nations and represents a geographically stratified and broadly representative selection of sites across the African, American and Asia-Pacific tropics (Supplementary Fig. 1). The reserves ranged from 160 ha to 3.6 million ha in size, but most $(85 \%)$ exceeded 10,000 ha in area (median $=99,350$ ha; lower decile $=7,000 \mathrm{ha}$; upper decile $=750,000 \mathrm{ha}$ ). The protected areas fall under various International Union for Conservation of Nature (IUCN) reserve classifications. Using data from the World Database on Protected Areas (http://www.wdpa.org), we found no significant difference $(P=0.13)$ in the relative frequency of high-protection (IUCN Categories I-IV), multiple-use (Categories V-VI) and

Table 1 | The 31 animal and plant guilds, and the 21 environmental drivers assessed both inside and immediately outside each protected area.

Guilds Potential environmental drivers

Broadly forest-dependent guilds Apex predators

Large non-predatory species

Primates

Opportunistic omnivorous mammals Rodents

Bats

Understory insectivorous birds

Raptorial birds

Larger frugivorous birds

Larger game birds

Lizards and larger reptiles

Venomous snakes

Non-venomous snakes

Terrestrial amphibians

Stream-dwelling amphibians

Freshwater fish

Dung beetles

Army or driver ants

Aquatic invertebrates

Large-seeded old-growth trees

Epiphytes

Other functional groups

Ecological specialists

Species requiring tree cavities

Migratory species

Disturbance-favouring guilds

Lianas and vines

Pioneer and generalist trees

Exotic animal species

Exotic plant species

Disease-vectoring invertebrates

Light-loving butterflies

Human diseases
Changes in natural-forest cover

Selective logging

Fires

Hunting

Harvests of non-timber forest products

Illegal mining

Roads

Automobile traffic

Exotic plantations

Human population density

Livestock grazing

Air pollution

Water pollution

Stream sedimentation

Soil erosion

River \& stream flows

Ambient temperature

Annual rainfall

Drought severity or intensity

Flooding

Windstorms 


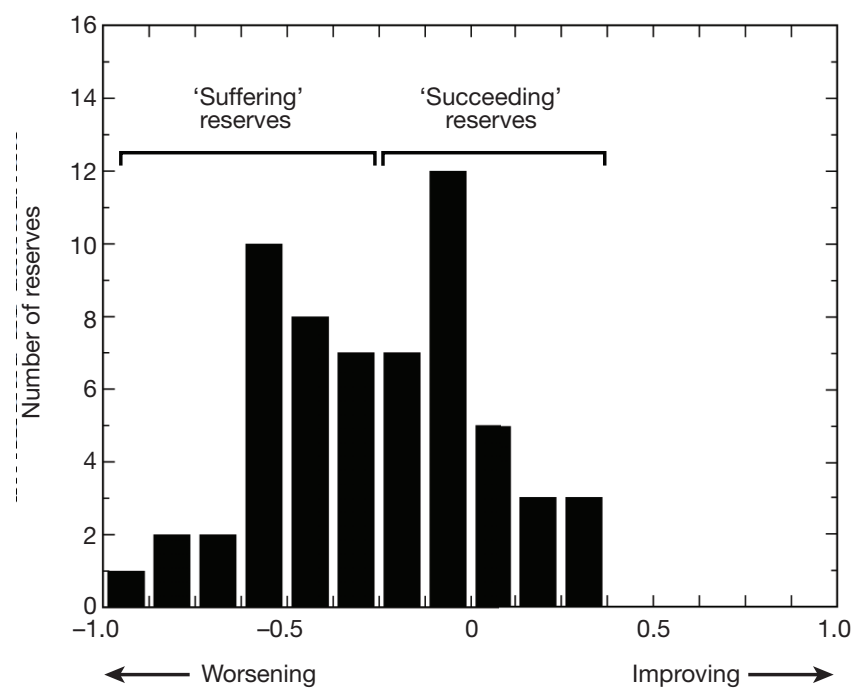

Figure $1 \mid$ Distribution of the 'reserve-health index' for 60 protected areas spanning the world's major tropical forest regions. This relative index averages changes in 10 well-studied guilds of animals and plants, including disturbanceavoiding and disturbance-favouring groups, over the past 20 to 30 years.

unclassified reserves between our sample of 60 reserves and all 16,038 reserves found in the same tropical nations (Supplementary Fig. 2). We also found no significant difference $(P=0.08)$ in the geographical isolation of our reserves (travel time to the nearest city with greater than 50,000 residents) relative to a random sample of 60 protected areas stratified across the same 36 nations (Supplementary Fig. 3).

We critically assessed the validity of our interview data by comparing them to 59 independent time-series data sets in which change in a single guild or environmental driver was assessed for one of our protected areas. Collectively, our meta-analysis included some data on 15 of the guilds, 13 of the drivers and 27 of the protected areas in our study (Supplementary Table 1). Most (86.4\%) of the independent data sets supported our interview results, and in no case did an independent test report a trend opposite in sign to our interview-based findings.

Our analyses suggest that the most sensitive guilds in tropical protected areas include apex predators, large non-predatory vertebrates, bats, stream-dwelling amphibians, terrestrial amphibians, lizards and larger reptiles, non-venomous snakes, freshwater fish, large-seeded old-growth trees, epiphytes and ecological specialists (all $P<0.0056$, with effect sizes ranging from -0.36 to -1.05 ; Supplementary Table 2). Several other groups were somewhat less vulnerable, including primates, understory insectivorous birds, large frugivorous birds, raptorial birds, venomous snakes, species that require tree cavities, and migratory species (all $P<0.05$, with effect sizes from -0.27 to -0.53 ). In addition, five groups increased markedly in abundance in the reserves, including pioneer and generalist trees, lianas and vines, invasive animals, invasive plants and human diseases (all $P<0.0056$, with effect sizes from 0.44 to 1.17 ).

To integrate these disparate data, we generated a 'reserve-health index' that focused on 10 of the best-studied guilds (data for each available at $\geq 80 \%$ of reserves), all of which seem to be sensitive to environmental changes in protected areas. Six of these are generally 'disturbance avoiders' (apex predators, large non-predatory vertebrates, primates, understory insectivorous birds, large frugivorous birds and large-seeded old-growth trees) and the remainder seem to be 'disturbance-favouring' groups (pioneer and generalist trees, lianas and vines, exotic animals and exotic plants). For each protected area, we averaged the mean values for each group, using negative values to indicate increases in abundance of the disturbance-favouring guilds.

The reserve-health index varied greatly among the different protected areas (Fig. 1). About four-fifths of the reserves had negative values, indicating some decline in reserve health. For $50 \%$ of all reserves this decline was relatively serious (mean score $<-0.25$ ), with the affected organisms being remarkable for their high functional and taxonomic diversity (Fig. 2). These included plants with varying growth forms and life-history strategies, and fauna that differed widely in body size, trophic level, foraging strategies, area needs, habitat use and other attributes. The remaining reserves generally exhibited much more positive outcomes for biodiversity (Fig. 2), although a few disturbance-favouring guilds, such as exotic plants and pioneer and generalist trees, often increased even within these areas.

An important predictor of reserve health was improving reserve management. According to our experts, reserves in which actual, on-the-ground protection efforts (see Supplementary Information) had increased over the past 20 to 30 years generally fared better than those in which protection had declined; a relationship that was consistent across all three of the world's major tropical regions (Fig. 3). Indeed, on-the-ground protection has increased in more than half of the reserves over the past 20 to 30 years, and this is assisting efforts to limit threats such as deforestation, logging, fires and hunting within these reserves (Supplementary Table 3), relative to areas immediately outside (Supplementary Table 4).

However, our findings show that protecting biodiversity involves more than just safeguarding the reserves themselves. In many instances, the landscapes and habitats surrounding reserves are under imminent threat ${ }^{5,6,15}$ (Fig. 4 and Supplementary Tables 3 and 4). For example, $85 \%$ of our reserves suffered declines in surrounding forest cover in the last 20 to 30 years, whereas only $2 \%$ gained surrounding forest. As shown by general linear models (Supplementary Table 5), such changes can seriously affect reserve biodiversity. Among the

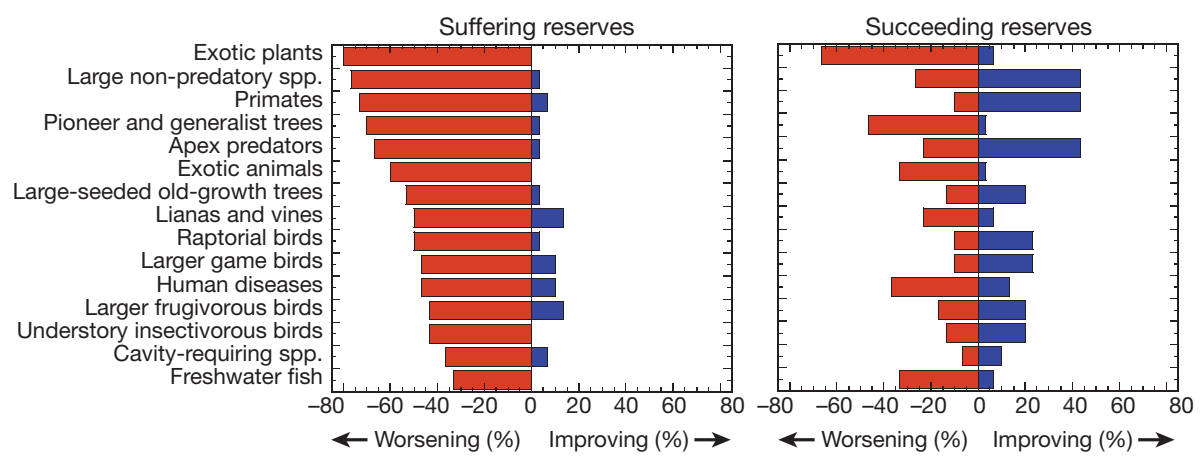

Figure $2 \mid$ Percentages of reserves that are worsening versus improving for key disturbance-sensitive guilds, contrasted between 'suffering' and 'succeeding' reserves (which are distinguished by having lower $(<-0.25)$ versus higher $(\geq-0.25)$ values for the reserve-health index, respectively). For disturbance- favouring organisms such as exotic plants and animals, pioneer and generalist trees, lianas and vines, and human diseases, the reserve is considered to be worsening if the group increased in abundance. For any particular guild, reserves with missing or zero values (no trend) are not included. 


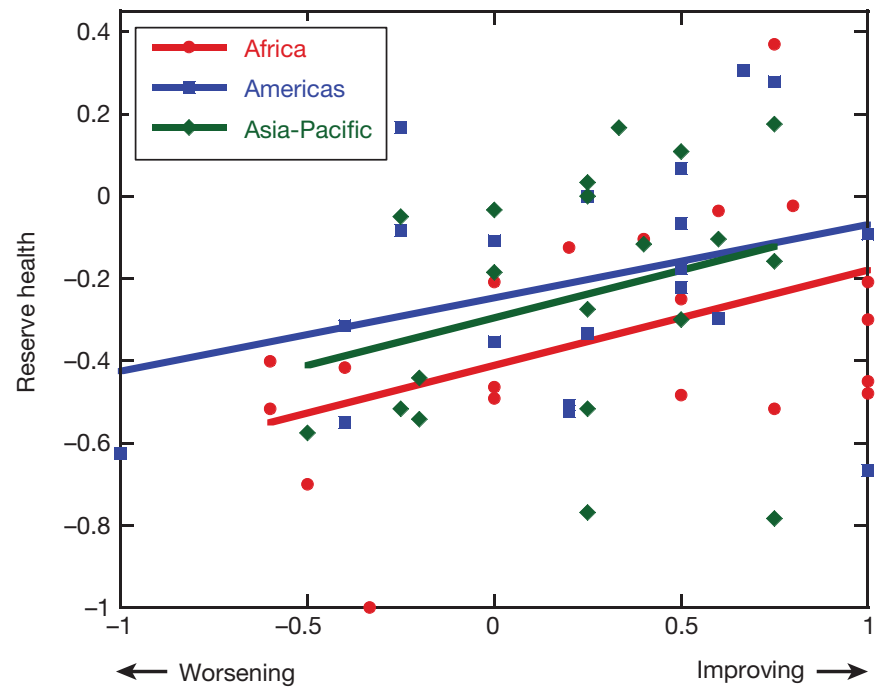

Change in reserve protection

Figure $3 \mid$ Effects of improving on-the-ground protection on a relative index of reserve health. This positive relationship held across all three tropical continents (a general linear model showed that the protection term was the most effective predictor of reserve health (Akaike's information criterion weight, 0.595; deviance explained, $11.4 \%$ ), with the addition of 'continent' providing only a small improvement in model fit (Akaike's information criterion weight, 0.317 ; deviance explained, $16.3 \%$ ).

potential drivers of declining reserve health, three of the most important predictors involved ecological changes outside reserves (declining forest cover, increasing logging and increasing fires outside reserves; Supplementary Fig. 6). The remainder involved changes within reserves (particularly declining forest cover and increasing hunting, as well as increasing logging and harvests of non-timber forest products; Supplementary Table 5).

Thus, changes both inside and outside reserves determine their ecological viability, with forest disruption (deforestation, logging and fires), and overexploitation of wildlife and forest resources (hunting and harvests of non-timber forest products) having the greatest direct negative impacts. Other environmental changes, such as air and water pollution, increases in human population densities and climatic change (changes in total rainfall, ambient temperature, droughts and windstorms) generally had weaker or more indirect effects over the last 20 to 30 years (Supplementary Table 5).

Environmental degradation occurring around a protected area could affect biodiversity in many ways, such as by increasing reserve isolation, area and edge effects ${ }^{15-19}$. However, we discovered that its effects are also more insidious: they strongly predispose the reserve itself to similar kinds of degradation. Nearly all (19 of 21) of the environmental drivers had positive slopes when comparing their direction and magnitude inside versus outside reserves (Fig. 5). Among these, 13 were significant even with stringent Bonferroni corrections $(P<0.0071)$ and 17 would have been significant if tested individually $(P<0.05)$. As expected, the associations were strongest for climate parameters but were also strong for variables describing air and water pollution, stream sedimentation, hunting, mining, harvests of non-timber forest products and fires. To a lesser extent, trends in forest cover, human populations, road expansion and automobile traffic inside reserves also mirror those occurring outside reserves (Fig. 5).

Our findings signal that the fates of tropical protected areas will be determined by environmental changes both within and around the reserves, and that pressures inside reserves often closely reflect those occurring around them. For many reasons, larger reserves should be more resilient to such changes ${ }^{15-22}$, although we found that removing the effects of reserve area statistically did not consistently weaken the correlations between changes inside versus outside protected areas (Supplementary Table 6).

Our study reveals marked variability in the health of tropical protected areas. It indicates that the best strategy for maintaining biodiversity within tropical reserves is to protect them against their major proximate threats, particularly habitat disruption and overharvesting. However, it is not enough to confine such efforts to reserve interiors while ignoring their surrounding landscapes, which are often being rapidly deforested, degraded and overhunted ${ }^{5,6,13,15}$ (Fig. 5). A failure to limit interrelated internal and external threats could predispose reserves to ecological decay, including a taxonomically and functionally
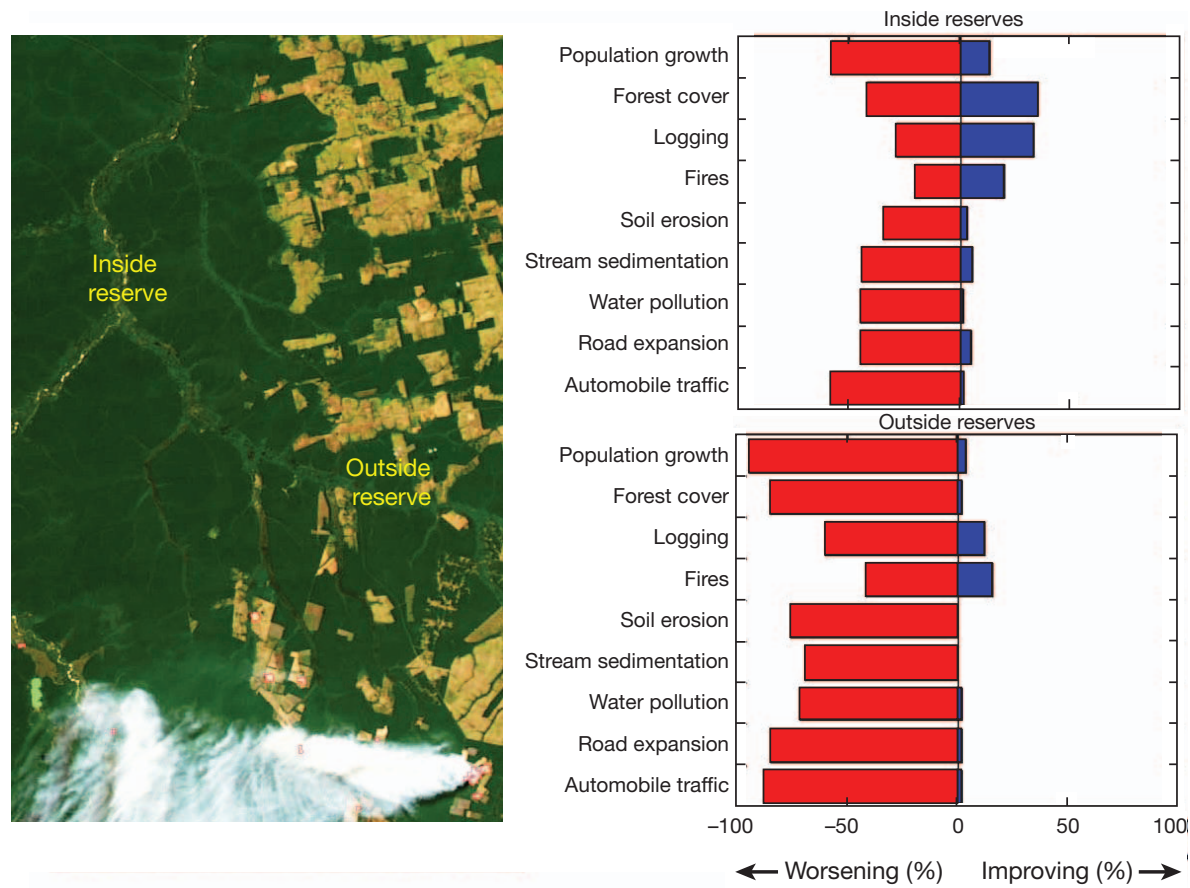

Figure $4 \mid$ Comparison of ecological changes inside versus outside protected areas, for selected environmental drivers. The image is an example of the strong distinction in disturbance inside versus outside a reserve. The bars show the percentages of reserves with improving versus worsening conditions. 


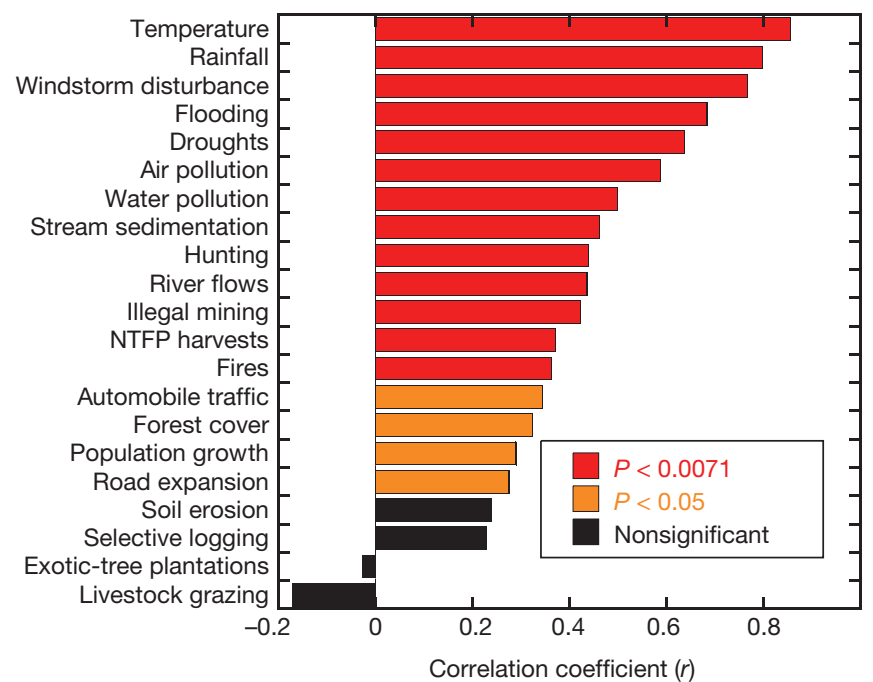

Figure 5 Pearson correlations comparing the direction and strength of 21 environmental drivers inside versus outside tropical protected areas. NTFP, non-timber forest products.

sweeping array of changes in species communities (Fig. 2) and an erosion of fundamental ecosystem processes ${ }^{16,18,23}$.

Protected areas are a cornerstone of efforts to conserve tropical biodiversity ${ }^{3,4,13,21}$. It is not our intent to diminish their crucial role but to highlight growing challenges that could threaten their success. The vital ecological functions of wildlife habitats surrounding protected areas create an imperative, wherever possible, to establish sizeable buffer zones around reserves, maintain substantial reserve connectivity to other forest areas and promote lower-impact land uses near reserves by engaging and benefiting local communities ${ }^{4,15,24-27}$. A focus on managing both external and internal threats should also increase the resilience of biodiversity in reserves to potentially serious climatic change $e^{28-30}$ in the future.

\section{METHODS SUMMARY}

Our interview protocol, rationale, questionnaire and data analyses are detailed in the Supplementary Information. We selected protected areas broadly to span the African, American and Asia-Pacific tropics (Supplementary Fig. 1), focusing on sites with mostly tropical or subtropical forest that had at least 10 refereed publications and 4-5 researchers with long-term experience who could be identified and successfully interviewed.

We devised a robust and relatively simple statistical approach to assess temporal changes in the abundance of each guild and in each potential environmental driver across our reserve network (see Supplementary Information). In brief, this involved asking each expert whether each variable had markedly increased, remained stable or markedly declined for each reserve. These responses were scored as 1, 0 and -1 , respectively. For each response, the expert was also asked to rank their degree of confidence in their knowledge. After discarding responses with lower confidence, scores from the individual experts at each site were pooled to generate a mean value (ranging from -1.0 to 1.0) to estimate the long-term trend for each variable.

The means for each variable across all 60 sites were then pooled into a single data distribution. We used bootstrapping (resampling with replacement; 100,000 iterations) to generate confidence intervals for the overall mean of the data distribution. If the confidence intervals did not overlap zero, then we interpreted the trend as being non-random. Because we tested many different guilds, we used a stringent Bonferroni correction $(P \leq 0.0056)$ to reduce the likelihood of Type I statistical errors, although we also identified guilds that showed evidence of trends $(P \leq 0.05)$ if tested individually. For comparison, we estimated effect sizes (bootstrapped mean divided by s.d., with negative values indicating declines) for changes in guild abundances and for potential drivers inside and outside reserves (Supplementary Tables 2-4).

\section{Received 24 February; accepted 14 June 2012.}

Published online 25 July; corrected online 12 September 2012 (see full-text HTML version for details).

1. Pimm, S. L. \& Raven, P. R. Biodiversity: extinction by numbers. Nature $\mathbf{4 0 3 ,}$ 843-845 (2000).
2. Bradshaw, C. J. A., Sodhi, N. S. \& Brook, B. W. Tropical turmoil-a biodiversity tragedy in progress. Front. Ecol. Environ 7, 79-87 (2009).

3. Gibson, L. et al. Primary forests are irreplaceable for sustaining tropical biodiversity. Nature 478, 378-381 (2011).

4. Bruner, A. G., Gullison, R., Rice, R. \& da Fonseca, G. Effectiveness of parks in protecting tropical biodiversity. Science 291, 125-128 (2001).

5. Curran, L. M. et al. Lowland forest loss in protected areas of Indonesian Borneo. Science 303, 1000-1003 (2004).

6. DeFries, R., Hansen, A., Newton, A. C. \& Hansen, M. C. Increasing isolation of protected areas in tropical forests over the past twenty years. Ecol. Appl. 15, 19-26 (2005).

7. Lovejoy, T. E. Protected areas: A prism for a changing world. Trends Ecol. Evol. 21 329-333 (2006).

8. Possingham, H. P., Wilson, K. A., Andelman, S. J. \& Vynne, C. H. in Principles of Conservation Biology (eds Groom, M. J., Meffe, G. K. \& Carroll, C. R.) (Sinauer, 2006),

9. Joppa, L. N., Loarie, S. \& Pimm, S. L. On the protection of "protected areas". Proc Natl Acad. Sci. USA 105, 6673-6678 (2008).

10. Jenkins, C. N. \& Joppa, L. Expansion of the global terrestrial protected area system. Biol. Conserv. 142, 2166-2174 (2009).

11. Asner, G. P. etal. Selective logging in the Brazilian Amazon. Science 310, 480-482 (2005).

12. Wright, S. J., Sanchez-Azofeifa, G., Portillo-Quintero, C. \& Davies, D. Poverty and corruption compromise tropical forest reserves. Ecol. Appl. 17, 1259-1266 (2007).

13. Adeney, J. M., Christensen, N. \& Pimm, S. L. Reserves protect against deforestation fires in the Amazon. PLoS ONE 4, e5014 (2009).

14. Peres, C. A., Barlow, J. \& Laurance, W. F. Detecting anthropogenic disturbance in tropical forests. Trends Ecol. Evol. 21, 227-229 (2006).

15. Hansen, A. J. \& DeFries, R. Ecological mechanisms linking protected areas to surrounding lands. Ecol. Appl. 17, 974-988 (2007).

16. Laurance, W. F. et al. Biomass collapse in Amazonian forest fragments. Science 278, 1117-1118 (1997).

17. Woodroffe, R. \& Ginsberg, J. R. Edge effects and the extinction of populations inside protected areas. Science 280, 2126-2128 (1998).

18. Terborgh, J. et al. Ecological meltdown in predator-free forest fragments. Science 294, 1923-1926 (2001).

19. Laurance, W. F. et al. The fate of Amazonian forest fragments: a 32-year investigation. Biol. Conserv. 144, 56-67 (2011).

20. Brooks, T. M., Pimm, S. L. \& Oyugi, J. O. Time lag between deforestation and bird extinction in tropical forest fragments. Conserv. Biol. 13, 1140-1150 (1999).

21. Peres, C. A. Why we need megareserves in Amazonia. Conserv. Biol. 19, 728-733 (2005).

22. Maiorano, L., Falcucci, A. \& Boitani, L. Size-dependent resistance of protected areas to land-use change. Proc. R. Soc. B 275, 1297-1304 (2008).

23. Estes, J. A. et al. Trophic downgrading of Planet Earth. Science 333, 301-306 (2011).

24. Wells, M. P. \& McShane, T. O. Integrating protected area management with local needs and aspirations. Ambio 33, 513-519 (2004).

25. Scherl, L. M. etal. Can Protected Areas Contribute to Poverty Reduction? Opportunities and Limitations (IUCN, 2004).

26. Chan, K. M. A. \& Daily, G. C. The payoff of conservation investments in tropical countryside. Proc. Natl Acad. Sci. USA 105, 19342-19347 (2008)

27. Porter-Bolland, L. et al. Community-managed forests and protected areas: an assessment of their conservation effectiveness across the tropics. For. Ecol. Manage. 256, 6-17 (2012).

28. Thomas, C. D. et al. Extinction risk from climate change. Nature 427, 145-148 (2004).

29. Sekercioglu, C. H., Schneider, S. H., Fay, J. P. \& Loarie, S. R. Climate change, elevational range shifts, and bird extinctions. Conserv. Biol. 22, 140-150 (2008).

30. Shoo, L. P. et al. Targeted protection and restoration to conserve tropical biodiversity in a warming world. Glob. Change Biol. 17, 186-193 (2011).

Supplementary Information is linked to the online version of the paper at www.nature.com/nature.

Acknowledgements The study was supported by James Cook University, the Smithsonian Tropical Research Institute, an Australian Laureate Fellowship (to W.F.L.) and NSF grant RCN-0741956. We thank A. Bruner, R. A. Butler, G. R. Clements, R. Condit, C. N. Cook, S. Goosem, J. Geldmann, L. Joppa, S. L. Pimm and O. Venter for comments.

Author Contributions W.F.L. conceived the study and coordinated its design, analysis and manuscript preparation. D.C.U., J.R. and M.K. conducted the interviews; C.J.A.B. assisted with data analysis and some writing; and S.P.S., S.G.L., M.C. and W.L. organized data or collected metadata. The remaining authors provided detailed interviews on protected areas and offered feedback on the manuscript.

Author Information Reprints and permissions information is available at www.nature.com/reprints. The authors declare no competing financial interests. Readers are welcome to comment on the online version of this article at www.nature.com/nature. Correspondence and requests for materials should be addressed to W.F.L. (bill.laurance@jcu.edu.au).

William F. Laurance ${ }^{1,2}$, D. Carolina Useche ${ }^{2}$, Julio Rendeiro ${ }^{2}$, Margareta Kalka ${ }^{2}$, Corey J. A. Bradshaw ${ }^{3}$, Sean P. Sloan ${ }^{1}$, Susan G. Laurance ${ }^{1}$, Mason Campbell ${ }^{1}$, Kate 
Abernethy $4^{4}$, Patricia Alvarez $z^{5}$, Victor Arroyo-Rodriguez ${ }^{6}$, Peter Ashton 7 , Julieta Benítez-Malvido ${ }^{6}$, Allard Blom ${ }^{8}$, Kadiri S. Bobo ${ }^{9}$, Charles H. Cannon ${ }^{10}$, Min Cao $^{10}$, Richard Carroll ${ }^{8}$, Colin Chapman ${ }^{11}$, Rosamond Coates $^{12}$, Marina Cords ${ }^{13}$, Finn Danielsen ${ }^{14}$, Bart De Dijn ${ }^{15}$, Eric Dinerstein ${ }^{8}$, Maureen A. Donnelly ${ }^{16}$, David Edwards ${ }^{1}$ Felicity Edwards ${ }^{1}$, Nina Farwig ${ }^{17}$, Peter Fashing ${ }^{18}$, Pierre-Michel Forget ${ }^{19}$, Mercedes Foster ${ }^{20}$, George Gale ${ }^{21}$, David Harris ${ }^{22}$, Rhett Harrison ${ }^{10}$, John Hart ${ }^{23}$, Sarah Karpanty ${ }^{24}$, W. John Kress ${ }^{25}$, Jagdish Krishnaswamy ${ }^{26}$, Willis Logsdon ${ }^{1}$, Jon Lovett ${ }^{27}$ William Magnusson ${ }^{28}$, Fiona Maisels $s^{4,29}$, Andrew R. Marshall ${ }^{30}$, Deedra McClearn ${ }^{31}$, Divya Mudappa ${ }^{32}$, Martin R. Nielsen ${ }^{33}$, Richard Pearson ${ }^{34}$, Nigel Pitman ${ }^{5}$, Jan van der Ploeg ${ }^{35}$. Andrew Plumptre ${ }^{36}$, John Poulsen ${ }^{37}$, Mauricio Quesada ${ }^{6}$, Hugo Rainey ${ }^{29}$ Douglas Robinson ${ }^{38}$, Christiane Roetgers ${ }^{1}$, Francesco Rovero ${ }^{39}$, Frederick Scatena ${ }^{40}$ Christian Schulze ${ }^{41}$, Douglas Sheil ${ }^{42}$, Thomas Struhsaker ${ }^{5}$, John Terborgh ${ }^{5}$, Duncan Thomas $^{38}$, Robert Timm ${ }^{43}$, J. Nicolas Urbina-Cardona ${ }^{44}$, Karthikeyan Vasudevan ${ }^{45}$, $S$. Joseph Wright ${ }^{2}$, Juan Carlos Arias-G. ${ }^{46}$, Luzmila Arroyo ${ }^{47}$, Mark Ashton ${ }^{48}$, Philippe Auze $^{11}$, Dennis Babaasa ${ }^{49}$, Fred Babweteera ${ }^{50}$, Patrick Baker ${ }^{51}$, Olaf Banki ${ }^{52}$, Margot Bass $^{53}$, Inogwabini Bila-Isia ${ }^{54}$, Stephen Blake ${ }^{29}$, Warren Brockelman ${ }^{55}$, Nicholas Brokaw ${ }^{56}$, Carsten A. Brühl ${ }^{57}$, Sarayudh Bunyavejchewin ${ }^{58}$, Jung-Tai Chao ${ }^{59}$, Jerome Chave $^{60}$, Ravi Chellam ${ }^{61}$, Connie J. Clark ${ }^{5}$, José Clavijo ${ }^{62}$, Robert Congdon ${ }^{34}$, Richard Corlett $^{63}$, H. S. Dattaraja ${ }^{64}$, Chittaranjan Dave ${ }^{65}$, Glyn Davies ${ }^{66}$, Beatriz de Mello Beisiegel ${ }^{67}$, Rosa de Nazaré Paes da Silva ${ }^{68}$, Anthony Di Fiore ${ }^{69}$, Arvin Diesmos ${ }^{70}$, Rodolfo Dirzo ${ }^{71}$, Diane Doran-Sheehy ${ }^{72}$, Mitchell Eaton ${ }^{73}$, Louise Emmons ${ }^{25}$ Alejandro Estrada ${ }^{12}$, Corneille Ewango ${ }^{74}$, Linda Fedigan ${ }^{75}$, François Feer ${ }^{19}$, Barbara Fruth $^{76}$, Jacalyn Giacalone Willis ${ }^{77}$, Uromi Goodale ${ }^{78}$, Steven Goodman ${ }^{79}$, Juan C. Guix $^{80}$, Paul Guthiga ${ }^{81}$, William Haber ${ }^{82}$, Keith Hamer ${ }^{83}$, Ilka Herbinger ${ }^{84}$, Jane Hill ${ }^{30}$ Zhongliang Huang ${ }^{85}$, I Fang Sun ${ }^{86}$, Kalan Ickes ${ }^{87}$, Akira Itoh ${ }^{88}$, Natália Ivanauskas ${ }^{89}$, Betsy Jackes ${ }^{34}$, John Janovec ${ }^{90}$, Daniel Janzen ${ }^{40}$, Mo Jiangming ${ }^{11}$, Chen Jin ${ }^{10}$, Trevor Jones $^{92}$, Hermes Justiniano ${ }^{93}$, Elisabeth Kalko ${ }^{94} 4$, Aventino Kasangaki ${ }^{95}$, Timothy Killeen $^{96}$, Hen-biau King ${ }^{97}$, Erik Klop ${ }^{98}$, Cheryl Knott ${ }^{99}$, Inza Koné ${ }^{100}$, Enoka Kudavidanage ${ }^{63}$, José Lahoz da Silva Ribeiro ${ }^{101}$, John Lattke ${ }^{102}$, Richard Laval ${ }^{103}$ Robert Lawton ${ }^{104}$, Miguel Leal ${ }^{105}$, Mark Leighton ${ }^{106}$, Miguel Lentino ${ }^{107}$, Cristiane Leone $^{108}$, Jeremy Lindsell ${ }^{109}$, Lee Ling-Ling ${ }^{110}$, K. Eduard Linsenmair ${ }^{111}$, Elizabeth W. Scott McGraw ${ }^{117}$, Roan McNab ${ }^{118}$, Luciano Montag ${ }^{119}$, Jo Myers Thompson ${ }^{120}$, Jacob Nabe-Nielsen ${ }^{121}$, Michiko Nakagawa ${ }^{122}$, Sanjay Nepal ${ }^{123}$, Marilyn Norconk ${ }^{124}$ Vojtech Novotny ${ }^{125}$, Sean O'Donnell ${ }^{126}$, Muse Opiang ${ }^{127}$, Paul Ouboter 128 , Kenneth Parker $^{129}$, N. Parthasarathy ${ }^{130}$, Kátia Pisciotta ${ }^{131}$, Dewi Prawiradilaga ${ }^{132}$, Catherine Pringle ${ }^{133}$, Subaraj Rajathurai ${ }^{134}$, Ulrich Reichard ${ }^{135}$, Gay Reinartz ${ }^{136}$, Katherine Renton ${ }^{137}$, Glen Reynolds ${ }^{138}$, Vernon Reynolds ${ }^{139}$, Erin Riley ${ }^{140}$, Mark-Oliver Rödel $^{141}$, Jessica Rothman ${ }^{142}$, Philip Round ${ }^{143}$, Shoko Sakai ${ }^{144}$, Tania Sanaiotti ${ }^{28}$, Tommaso Savini ${ }^{21}$, Gertrud Schaab ${ }^{145}$, John Seidensticker ${ }^{146}$, Alhaji Siaka ${ }^{147}$, Miles R. Silman ${ }^{148}$, Thomas B. Smith ${ }^{149}$, Samuel Soares de Almeida ${ }^{150}+$, Navjot Sodhi ${ }^{63}$ Craig Stanford ${ }^{151}$, Kristine Stewart ${ }^{152}$, Emma Stokes ${ }^{29}$, Kathryn E. Stoner ${ }^{153}$, Raman Sukumar ${ }^{154}$, Martin Surbeck ${ }^{76}$, Mathias Tobler ${ }^{90}$, Teja Tscharntke ${ }^{155}$, Andrea Turkalo ${ }^{156}$, Govindaswamy Umapathy ${ }^{157}$, Merlijn van Weerd ${ }^{35}$, Jorge Vega Rivera ${ }^{137}$ Meena Venkataraman ${ }^{158}$, Linda Venn ${ }^{159}$, Carlos Verea ${ }^{160}$, Carolina Volkmer de Castilho ${ }^{161}$, Matthias Waltert ${ }^{155}$, Benjamin Wang ${ }^{149}$, David Watts ${ }^{48}$, William Weber ${ }^{29}$ Paige West ${ }^{13}$, David Whitacre ${ }^{162}$, Ken Whitney ${ }^{163}$, David Wilkie ${ }^{29}$, Stephen Williams ${ }^{34}$, Debra D. Wright ${ }^{115}$, Patricia Wright ${ }^{164}$, Lu Xiankai ${ }^{91}$, Pralad Yonzon ${ }^{165} \$$ \& Franky Zamzani $^{166}$

${ }^{1}$ Centre for Tropical Environmental and Sustainability Science (TESS) and School of Marine and Tropical Biology, James Cook University, Cairns, Queensland 4878, Australia. ${ }^{2}$ Smithsonian Tropical Research Institute, Balboa, Ancón, Panama. ${ }^{3}$ School of Earth and Environmental Sciences, University of Adelaide, Adelaide, South Australia 5005, Australia. ${ }^{4}$ Stirling University, Stirling FK9 4LA, UK. ${ }^{5}$ Duke University, Durham, North Carolina 27705, USA. ${ }^{6}$ Universidad Nacional Autónoma de México (UNAM), Morelia, Mexico. ${ }^{7}$ Royal Botanic Gardens, Kew, Richmond TW9 3AB, UK. ${ }^{8}$ World Wildlife Fund (WWF), Washington DC 20037, USA. ${ }^{9}$ University of Dschang, Dschang, Cameroon.

${ }^{10}$ Xishuangbanna Tropical Botanical Garden, Yunnan 666303, People's Republic of China. ${ }^{11}$ McGill University, Montreal H3A 2T7, Canada. ${ }^{12}$ Estación de Biologia Tropical Los Tuxtlas, Universidad Nacional Autónoma de México, Veracruz 95701, Mexico. ${ }^{13}$ Columbia University, New York, New York 10027, USA. ${ }^{14}$ Nordic Foundation for Development and Ecology, DK-1159 Copenhagen, Denmark. ${ }^{15}$ Bart De Dijn Environmental Consultancy, Paramaribo, Suriname. ${ }^{16}$ Florida International University, Miami, Florida 33199, USA. ${ }^{17}$ Philipps-Universität Marburg, Marburg 35043, Germany. ${ }^{18}$ California State University, Fullerton, California 92834, USA. ${ }^{19}$ Museum Natural d'Histoire Naturelle, 91800 Brunoy, France. ${ }^{20}$ US Geological Survey, Smithsonian Institution, Washington DC 20013, USA. ${ }^{21}$ King Mongkut's University of Technology Thonburi, Bangkok 10150, Thailand. ${ }^{22}$ Royal Botanic Garden, Edinburgh, Scotland EH3 5 LR, UK. ${ }^{23}$ Tshuapa-Lomami-Lualaba Project, Kinshasa, Democratic Republic of Congo. ${ }^{24}$ Virginia Tech University, Blacksburg, Virginia 24061, USA. ${ }^{25}$ National Museum of Natural History, Smithsonian Institution, Washington DC 20013, USA. ${ }^{26}$ Ashoka Trust for Research in Ecology and the Environment (ATREE), Bangalore 560064, India. ${ }^{27}$ University of Twente, Enschede, Netherlands. ${ }^{28}$ Instituto Nacional de Pesquisas da Amazônia (INPA), Manaus, Amazonas 69011-970, Brazil. ${ }^{29}$ Wildlife Conservation Society, Bronx, New York 10460, USA. ${ }^{30}$ University of York, Heslington, York YO10 5DD, UK. ${ }^{31}$ La Selva Biological Station, San Pedro, Costa Rica. ${ }^{32}$ Nature Conservation Foundation, Mysore 570002 , India. ${ }^{33}$ University of Copenhagen, Copenhagen, Denmark. ${ }^{34}$ James Cook University, Townsville, Queensland 4811, Australia. ${ }^{35}$ Leiden University, Leiden, Netherlands. ${ }^{36}$ Wild life Conservation Society, Kampala, Uganda. ${ }^{37}$ Woods Hole Research Center, Falmouth, Massachusetts 02540, USA. ${ }^{38}$ Oregon State University, Corvallis, Oregon 97331, USA. ${ }^{39}$ Museo delle Scienze, 38122 Trento, Italy. ${ }^{40}$ University of Pennsylvania, Philadelphia, Pennsylvania 19104, USA. ${ }^{41}$ University of Vienna, 1030 Vienna, Austria. ${ }^{42}$ Bwindi Impenetrable National Park, Kabale, Uganda. ${ }^{43}$ University of Kansas, Lawrence, Kansas 66045, USA. ${ }^{44}$ Pontificia Universidad Javeriana, Bogotá, Colombia. ${ }^{45}$ Wildlife Institute of India, Dehradun, India. ${ }^{46}$ Unidad de Parques Nacionales Naturales de
Colombia, Bogotá, Colombia. ${ }^{47}$ Museo de Historia Natural Noel Kempff, Santa Cruz, Bolivia. ${ }^{48}$ Yale University, New Haven, Connecticut 06511, USA. ${ }^{49}$ Institute of Tropical Forest Conservation, Kabale, Uganda. ${ }^{50}$ Budongo Conservation Field Station, Masindi, Uganda. ${ }^{51}$ Monash University, Melbourne, Victoria 3800, Australia. ${ }^{52}$ Utrecht University, Utrecht, Netherlands. ${ }^{53}$ Finding Species, Takoma Park, Maryland 20912, USA. ${ }^{54}$ University of Kent, Kent CT2 7NZ, UK. ${ }^{55}$ Mahidol University Salaya, Nakhon Pathom 73170, Thailand. ${ }^{56}$ University of Puerto Rico, San Juan 00936, Puerto Rico. ${ }^{57}$ University Koblenz-Landau, D-76829 Landau, Germany. ${ }^{58}$ Department of National Parks, Chatuchak, Bangkok 10900, Thailand. ${ }^{59}$ Taiwan Forestry Research Institute, Tapei 10066, Taiwan. ${ }^{60}$ Université Paul Sabatier, Toulouse, France. ${ }^{61}$ Wildlife Conservation Society, Bangalore 560070, India. ${ }^{62}$ Universidad Central de Venezuela, Aragua, Venezuela. ${ }^{63}$ National University of Singapore, Singapore 117543. ${ }^{64}$ Indian Institute of Science, Bangalore 560012, India. ${ }^{65}$ World Wide Fund for Nature (WWF), New Delhi 110003 , India. ${ }^{66}$ World Wide Fund for Nature (WWF), Surrey GU7 1XR, UK. ${ }^{67}$ Instituto Chico Mendes de Conservação de Biodiversidade, Atibaia, São Paulo 12952-011, Brazil. ${ }^{68} \mathrm{O}$ Conselho Regional de Engenhara, Arquitetura e Agronomia do Pará, Belém, Pará, Brazil. ${ }^{69}$ University of Texas, Austin, Texas 78712, USA. ${ }^{70}$ National Museum of the Philippines, Manila, Phillipines. ${ }^{71}$ Stanford University, Stanford, California 94305, USA. ${ }^{72}$ State University of New York at Stony Brook, Stony Brook, New York 11794, USA. ${ }^{73}$ University of Colorado, Boulder, Colorado 80309, USA. ${ }^{74}$ Wildlife Conservation Society, Kinshasa, Democratic Republic of Congo. ${ }^{75}$ University of Calgary, Alberta T2N 1N4, Canada. ${ }^{76}$ Max Planck Institute for Evolutionary Anthropology, Leipzig, Germany. ${ }^{77}$ Montclair State University, Montclair, New Jersey 07043, USA. ${ }^{78}$ University of California, San Diego, California 92093, USA. ${ }^{79}$ Field Museum of Natural History, Chicago, Illinois 60605, USA. ${ }^{80}$ Universitat de Barcelona, 08028 Barcelona, Spain. ${ }^{81}$ Kenya Institute for Public Policy Research and Analysis, Nairobi, Kenya. ${ }^{82}$ Missouri Botanical Garden, St. Louis, Missouri 63166, USA. ${ }^{83}$ University of Leeds, Leeds LS2 9JT, UK. ${ }^{84}$ Wild Chimpanzee Foundation, Abidjan 23, Cote d'Ivoire. ${ }^{85}$ Dinghushan Biosphere Reserve, Zhaoqing, People's Republic of China. ${ }^{86}$ Tunghai University, Taichung 407, Taiwan. ${ }^{87}$ Clemson University, Clemson, South Carolina 29634, USA. ${ }^{88}$ Osaka City University, Osaka 558-8585, Japan. ${ }^{89}$ Instituto Florestal, São Paulo, São Paulo 02377-000, Brazil. ${ }^{90}$ Botanical Research Institute of Texas, Fort Worth, Texas 76107, USA. ${ }^{91}$ South China Botanical Garden, Guangzhou 510650, People's Republic of China. ${ }^{92}$ Anglia Ruskin University, Cambridge CB1 1PT, UK. ${ }^{93}$ Fundación para la Conservación del Bosque Chiquitano, Bolivia. ${ }^{94}$ University of Ulm, 89069 Ulm, Germany. ${ }^{95}$ Mbarara University of Science and Technology, Mbarara, Uganda. ${ }^{96}$ Conservation International, Arlington, Virginia 22202, USA. ${ }^{97}$ Society of Subtropical Ecology, Taipei, Taiwan. ${ }^{98}$ Royal Haskoning, Water and Ecology Group, Groningen, Netherlands. ${ }^{99}$ Boston University, Boston,

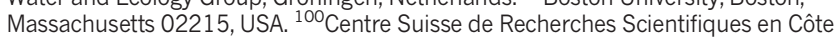
d'Ivoire, Abidjan, Côte d'Ivoire. ${ }^{101}$ Universidade Estadual de Londrina, Londrina, Paraná, Brazil. ${ }^{102}$ Universidad Central de Venezuela, Caracas, Venezuela. ${ }^{103}$ The Bat Jungle, Monteverde, Costa Rica. ${ }^{104}$ University of Alabama, Huntsville, Alabama 35899, USA. ${ }^{105}$ Boite Postale 7847, Libreville, Gabon. ${ }^{106} 95$ Warren Road, Framingham, Massachusetts 01702, USA. ${ }^{107}$ Colección Ornitológica Phelps, Caracas, Venezuela. ${ }^{108}$ Parque Estadual Horto Florestal, São Paulo, São Paulo 02377-000, Brazil. ${ }^{109}$ Royal Society for the Protection of Birds, Sandy SG19 2DL, UK. ${ }^{110}$ National Taiwan University, Taipei, Taiwan. ${ }^{111}$ University of Würzburg, Biocenter, D97074 Wuerzburg, Germany. ${ }^{112}$ Organization for Tropical Studies, Durham, North Carolina 27705, USA. ${ }^{113}$ USDA International Institute of Tropical Forestry, Río Piedras, Puerto Rico 00926. ${ }^{114}$ Makerere University, Kampala, Uganda. ${ }^{115}$ Green Capacity Inc., New Florence, Pennsylvania 15944, USA. ${ }^{116}$ Museu Paraense Emílio Goeldi, Belém, Pará 66040-170, Brazil. ${ }^{17}$ Ohio State University, Columbus, Ohio 43210, USA. ${ }^{118}$ Wildlife Conservation Society, Flores, Guatemala. ${ }^{119}$ Universidad Federal do Pará, Belém, Pará 66040-170, Brazil. ${ }^{120}$ Lukuru Wildlife Research Foundation, Kinshasa, Democratic Republic of Congo. ${ }^{121}$ Aarhus University, 4000 Roskilde, Denmark. ${ }^{122}$ Nagoya University, Nagoya, Japan. ${ }^{123}$ University of Waterloo, Waterloo, Ontario N2L 3G1, Canada. ${ }^{124}$ Kent State University, Kent, Ohio 44242, USA. ${ }^{125}$ Institute of Entomology, Ceske Budejovice, Czech Republic. ${ }^{126}$ University of Washington, Seattle, Washington 98195, USA. ${ }^{127}$ PNG Institute of Biological Research, Goroka, Papua New Guinea. ${ }^{128}$ University of Suriname, Paramaribo, Suriname.

${ }^{129} 113$-3885 Richet Rd, Prince George, British Columbia V2K 2J2, Canada.

${ }^{130}$ Pondicherry University, Puducherry 605-014, India. ${ }^{131}$ Fundação Florestal, São Paulo, São Paulo 02377-000, Brazil. ${ }^{132}$ Research Centre for Biology, Cibinong 16911. Indonesia. ${ }^{133}$ University of Georgia, Athens, Georgia 30602, USA. ${ }^{134}$ Strix Wildlife Consultancy, Singapore. ${ }^{135}$ Southern Illinois University, Carbondale, Illinois 62901, USA. ${ }^{136}$ Zoological Society of Milwaukee, Milwaukee, Wisconsin 53226, USA. ${ }^{137}$ Estación de Biologia Chamela, Universidad Nacional Autónoma de México, Jalisco 48980, Mexico. ${ }^{138}$ Danum Valley Field Centre, Sabah, Malaysia. ${ }^{139}$ Oxford University, Oxford BN26 5 UX, UK. ${ }^{140}$ San Diego State University, San Diego, California 92182, USA. ${ }^{141}$ Museum für Naturkunde, Berlin, Germany. ${ }^{142}$ City University of New York, New York 10065, USA. ${ }^{143}$ Mahidol University, Bangkok 10400, Thailand. ${ }^{144}$ Research Institute for Humanity and Nature, Kyoto, Japan. ${ }^{145}$ Karlsruhe University of Applied Sciences, Karlsruhe, Germany. ${ }^{146}$ National Zoological Park, Washington DC 20013, USA. ${ }^{147}$ Gola Forest Programme, Kenema, Sierra Leone. ${ }^{148}$ Wake Forest University, Winston-Salem, North Carolina 27106, USA. ${ }^{149}$ University of California, Los Angeles, California 90095, USA. ${ }^{150} \mathrm{Av}$. Maalhães Barata 376, Belém, Pará 66040-170, Brazil. ${ }^{151}$ University of Southern California, Los Angeles, California 90089, USA. ${ }^{152}$ Institute of Applied Ethnobotany, Pompano Beach, Florida 33069, USA. ${ }^{153}$ Texas A \& M University, Kingsville, Texas 78363, USA. ${ }^{154}$ Indian Institute of Science, Bangalore, India. ${ }^{155}$ Georg-August-Universität, Göttingen, Germany ${ }^{156}$ Wildlife Conservation Society, Bangui, Central African Republic. ${ }^{157}$ Centre for Cellular and Molecular Biology, Hyderabad, India. ${ }^{158} 701$, Vesta B, Lodha Paradise, Thane, India. ${ }^{159}$ Paluma Environmental Education Centre, Paluma, Queensland 4816, Australia. ${ }^{160}$ Universidad Central de Venezuela, Maracay, Venezuela. ${ }^{161}$ Embrapa Roraima, Boa Vista, Roraima, Brazil. ${ }^{162}$ Treasure Valley Math and Science Center, Boise, Idaho 83714, USA. ${ }^{163}$ Rice University, Houston, Texas 77005, USA. ${ }^{164}$ Stony Brook University, Stony Brook, New York 11794, USA. ${ }^{165}$ Resources Himalaya Foundation, Kathmandu, Nepal. ${ }^{166}$ Gunung Palung National Park, West Kalimantan, Indonesia.

tDeceased. 


\section{Supplementary Information}

\section{Methods}

Supplementary Figure 1 Names and locations of 60 protected areas stratified across the African, American and Asia-Pacific tropics.
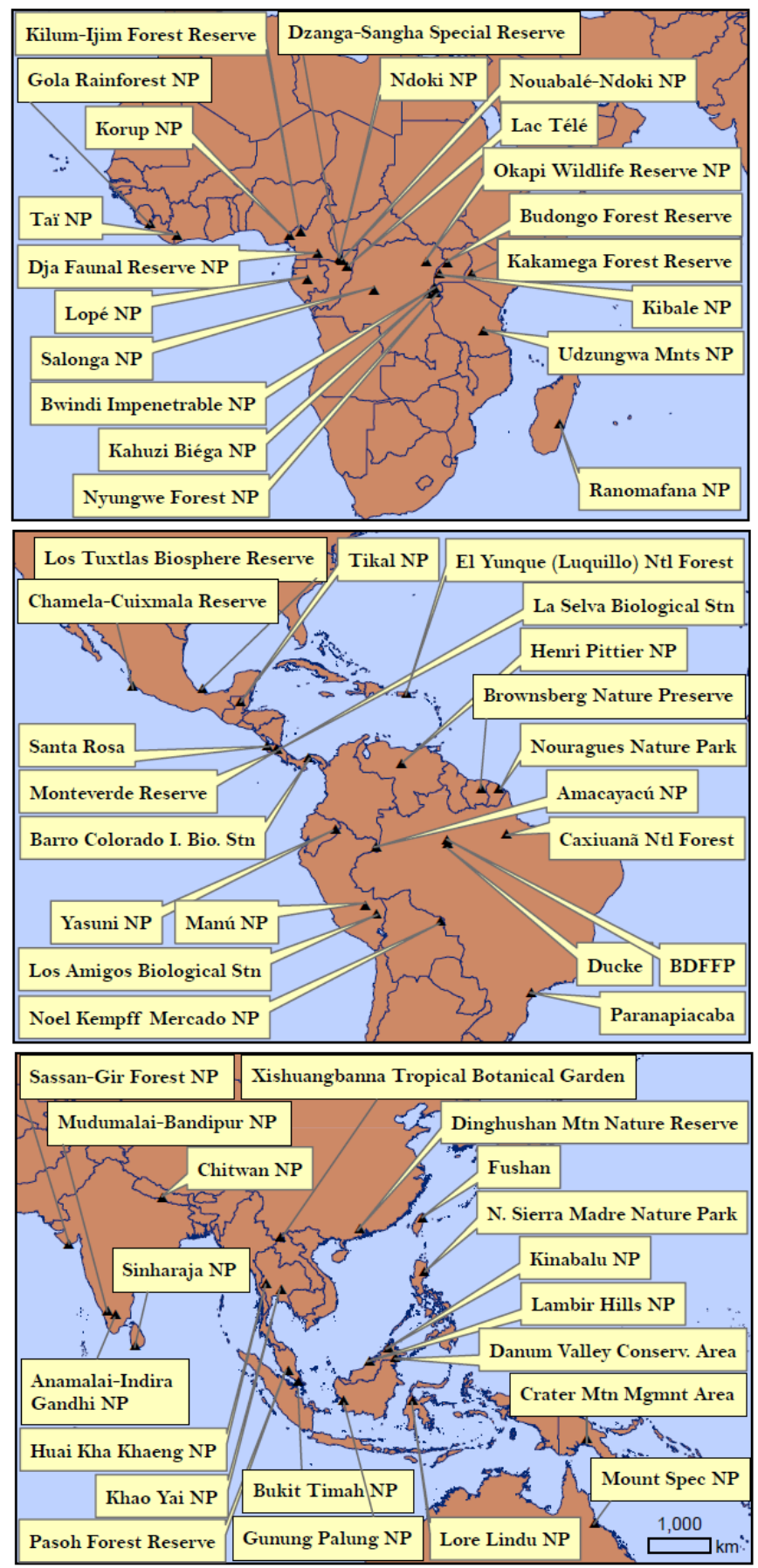


\section{Representativeness of study sites}

Our 60 tropical protected areas spanned 36 different nations. To provide an indication of the degree to which our sites were 'typical', we compared the relative frequency of reserves within 'high-protection' (IUCN Categories I-IV), 'multiple-use' (IUCN Categories V-VI), and unclassified categories between our sample and all 16,038 protected areas within the same nations from the World Database on Protected Areas (www.wdpa.org). We excluded China from this comparison because its reserve-classification scheme differs from that of other nations in having virtually no high-protection reserves; the ratio of multiple-use to high-protection reserves in China was 628.3, whereas ratios for all the other 35 nations were $<3.4$. We found no significant difference in the frequencies of reserves in the three different categories between our sample and expected values derived from all 16,038 reserves in the same nations $\left(G_{\text {adj }}=4.056\right.$, d.f. $=2, P=0.13$; $G$-test for goodness-of-fit, with Williams' correction for sample size) (Supplementary Fig. 2). Other kinds of data, such as the budgets and staffing for protected areas, were unavailable for most sites, precluding more in-depth comparisons of this nature.

Supplementary Figure 2 Number of high-protection (IUCN Categories I-IV), multiple-use (Categories V-VI) and unclassified protected areas in our study compared to expected values derived from all 16,038 protected areas in the same tropical nations.

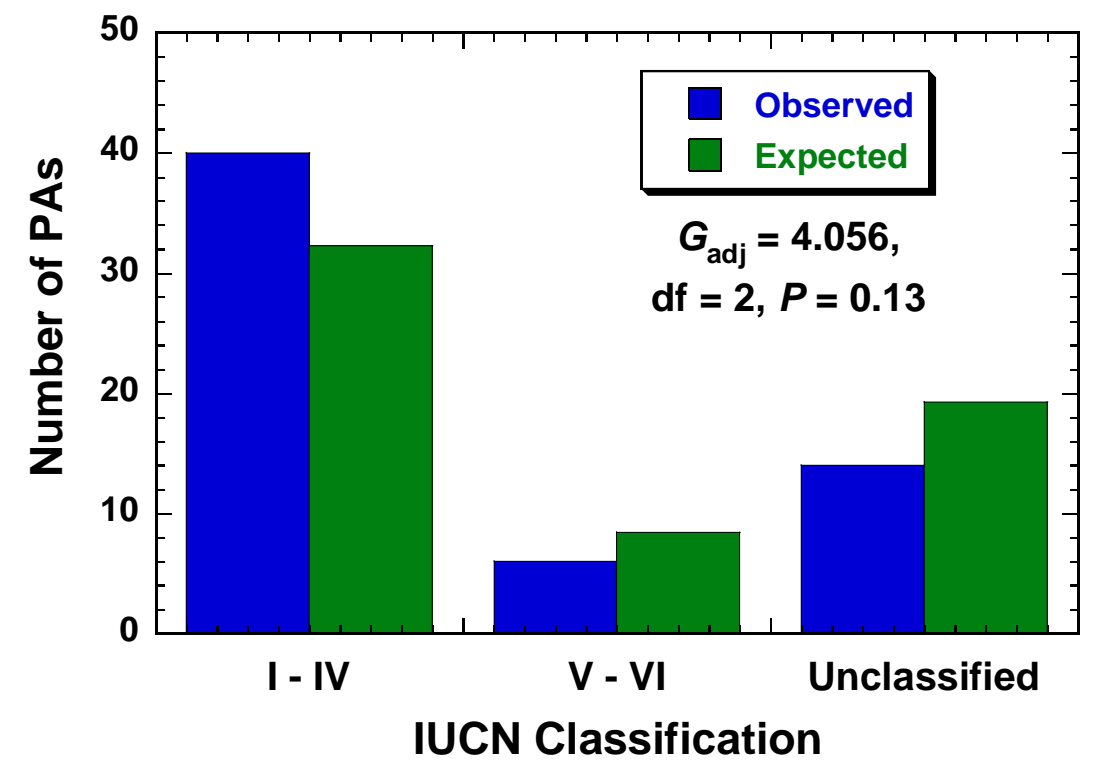

\section{Reserve isolation}

We also assessed the relative geographical isolation of the protected areas in our study, as measured by their distance to the nearest city. We did so because reserve isolation might influence the human pressures that a reserve experiences, and we wished to know whether our reserves were more or less isolated from nearby human populations than is typical of other reserves in the same nations.

For each of our 60 protected areas, we overlaid its boundary map onto a mapped surface of travel-time accessibility ${ }^{1}$. This surface estimates, for any point on Earth, the mean travel time in minutes required to reach the nearest city of $>50,000$ residents, using conventional local 
means such as automobiles, boats and hiking. The surface has a spatial resolution of 0.0083 decimal degrees (925 $\mathrm{m}$ at the equator), and we averaged the measurements for every pixel within each reserve to estimate its average isolation.

We then randomly selected 60 reserves for comparison. We stratified the randomly selected reserves across the same 36 nations in which our protected areas occur (choosing for each nation an equal number of random reserves as that found in our original sample). The randomly selected reserves were chosen from the World Database on Protected Areas (www.wdpa.org), using a Mersenne Twist random number generator with a random seed value. Marine protected areas were excluded from the random sample by considering only reserves whose centre-most point fell on land.

We found considerable overlap between the isolation of our reserves (mean $\pm \mathrm{SD}=741 \pm$ 761 minutes to the nearest city) and the randomly selected reserves (505 \pm 479 minutes) (Supplementary Fig. 3). The isolation values did not differ significantly on average, either when using a Mann-Whitney $U$-test $(P=0.071)$ or a two-way ANOVA that contrasted log-transformed isolation values between our sample and the random sites and also among the three major tropical regions (Africa, Americas, Asia-Pacific). This latter analysis revealed no significant difference between our reserves and the random sites $\left(F_{1,114}=3.19, P=0.077\right)$, but some difference among the three major regions $\left(F_{2,114}=3.33, P=0.039\right)$. In pairwise comparisons, reserves in Africa were more isolated ( $P<0.05$; Tukey's test) than those in the Asia-Pacific, with reserves in the Americas being intermediate and not significantly different from those in the other two regions.

Supplementary Figure 3 Comparison of the relative isolation (travelling time to the nearest city of $>50,000$ residents) between the 60 tropical forest protected areas in our study and a random sample of 60 protected areas stratified across the same 36 nations.

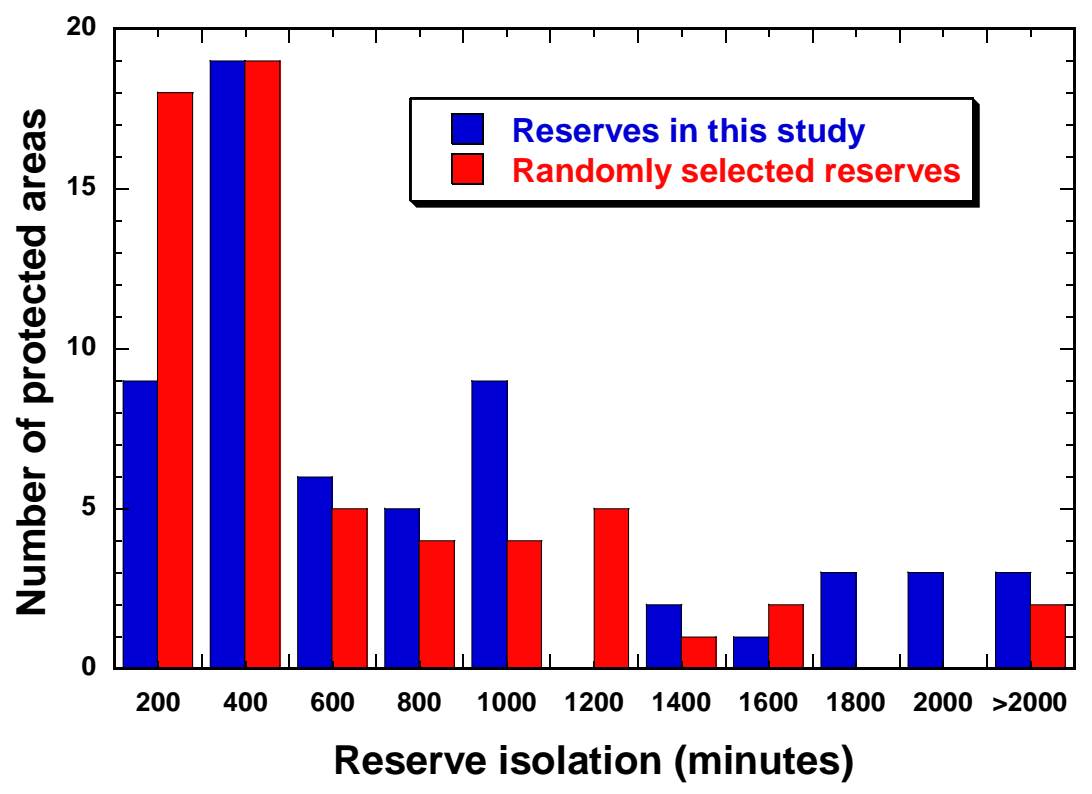




\section{Design of interviews}

We initially tested whether we could use research publications to assess the knowledge-base at our research sites, using two of the best-studied sites in the tropics, Barro Colorado Island in Panama and La Selva Biological Station in Costa Rica. Despite perusing the entire publication lists for both sites (up to early 2008), we found that recognized experts provided more comprehensive, up-to-date and time-efficient assessments. Moreover, the number of available refereed publications varied enormously among our 60 selected sites, from just 10 to > 3,300 papers. A reliance solely on publications would have imparted an obvious sampling bias when attempting to compare different sites, whereas experts are able to integrate a much wider range of knowledge based on personal observations, communications with other researchers and critically evaluating the relevant technical literature for their site.

Our 10-page interview form, coupled with a telephone or face-to-face interview, allowed us to plumb in detail the accumulated knowledge of our long-term experts. The form (attached below as Appendix 1) includes 120 individual questions, 60 of which have five-part answers. We carefully designed our interview form after consulting the relevant survey-method literature ${ }^{2-5}$ and with social-science experts who routinely conduct such surveys. Two of the most important potential biases to avoid are (a) diluting high-confidence responses with low-confidence responses, and (b) interviewing 'clusters' of closely affiliated, like-minded experts ${ }^{2,3}$. To minimize the first concern, we asked our experts to rank their level of confidence for each question they were asked ('speculative', 'good', 'high'). We discarded all speculative responses prior to analysis. To minimize the second concern, we used both technical publications and communications with an array of different individuals to identify our experts. These experts were predominantly ecologists, zoologists, and botanists with long-term field and empirical datacollection experience in their respective protected area.

Another concern in surveys such as ours is that respondents might provide biased responses either because they fear political or professional retribution ${ }^{2,3}$ or are personally invested in seeing the protected area succeed ${ }^{4}$. To minimize this concern, we offered all respondents complete anonymity, should they wish. We established the following conditions: if an outside party wishes to communicate with an expert for a particular reserve, they should contact the lead author of this study (William Laurance, email: bill.laurance@jcu.edu.au)who will then forward the request to the relevant expert. That expert can then either respond or ignore the request at their discretion. In practice, anonymity was not a concern for most of our experts, all of whom were offered, and most of whom accepted, co-authorship of this study (however, to err on the side of caution, none is explicitly associated with any particularly protected area in this study). We also considered and rejected the notion that these experts might have provided overly positive responses because they wanted to see the reserve succeed. In practice, many respondents (virtually all of whom were independent researchers, not park employees) expressed at least some concerns about the condition of their reserve. Further, our interview protocol was so exhaustive, specific and objective (with both written and verbal components and interviews of 45 different researchers per reserve) that it would have been difficult for any individual to obfuscate important changes in the reserve.

A final concern we had was whether 4-5 interviews were sufficient to identify the key trends at our different sites. To test this we conducted a 'saturation analysis', , which is designed to determine how much new information is being provided by each additional interview (Supplementary Fig. 4). First, we arbitrarily selected four of our response variables that varied widely. Second, for each of our 21 reserves for which we had 5 interviews, we pooled the 
interview data to generate mean scores for each variable. Third, we compared the mean score across these reserves from 1, 2, 3, and then 4 interviews to those generated by 5 interviews, using linear regression. As shown by the rapid and nonlinear rise in $R^{2}$ for each variable, the mean scores for each reserve rapidly converge on the final values after just 2-4 interviews. We conclude from this assessment that our regime of 4-5 interviews per site was sufficient to capture the most important aspects of available expert knowledge.

Supplementary Figure 4 Saturation curves for four representative response variables, compared to values achieved with randomly generated data.

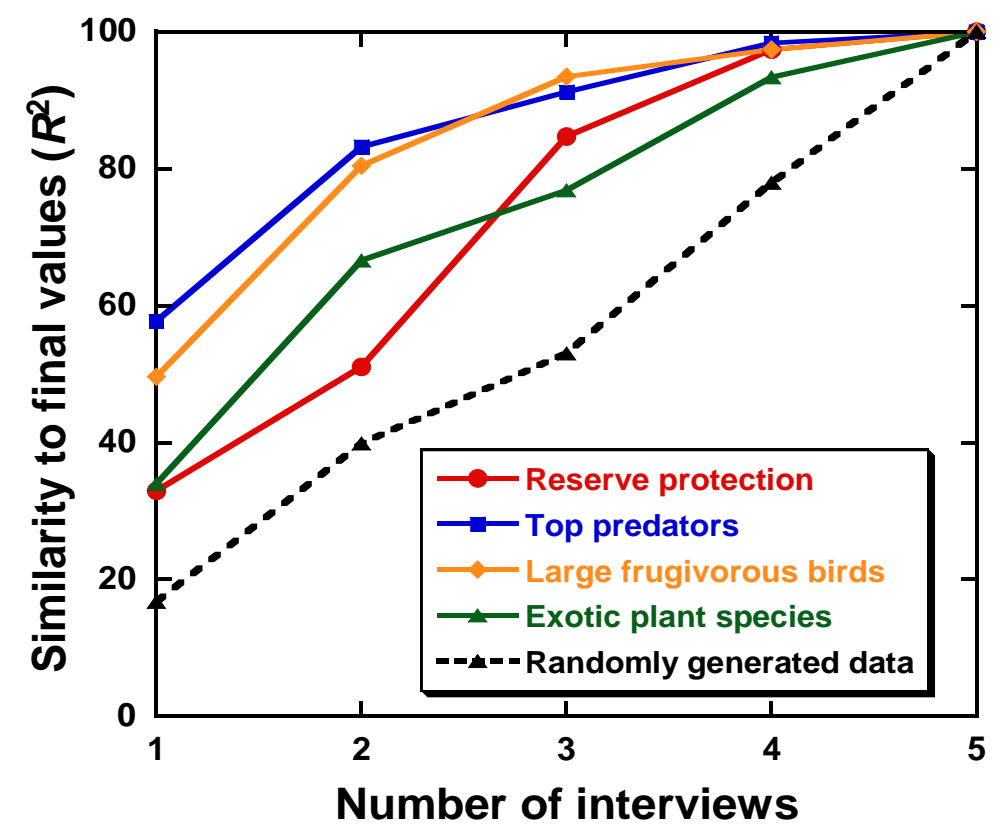

Statistical analyses

For ease of interpretation, we devised a robust and relatively simple statistical approach to assess temporal changes in each guild and potential environmental driver. We illustrate our strategy using the abundance of a single guild, apex predators, as an example. For each reserve, each expert was asked to indicate whether the overall abundance of apex predators had declined by at least $10-25 \%$, remained roughly stable, or increased by at least $10-25 \%$, over the past 20-30 years. These responses were scored as $-1,0$, and 1 , respectively ${ }^{\mathrm{A}}$. If an expert had no knowledge

\footnotetext{
${ }^{\text {A }}$ We originally collected quantitative data on each guild or environmental driver, using an ordinal scale (-3 = decline of > 50\%; -2 = decline of 25-50\%; -1 = decline of 10-25\%; $0=$ no change; 1 = increase of 10-25\%; 2 = increase of 25-50\%; $3=$ increase of $>50 \%$ ). However, we elected to simplify these data into a three-point scale $(+1,0,-1)$ because the validity of means and standard deviations derived from ordinal data has been questioned ${ }^{6}$ and because the threepoint and ordinal scales yielded virtually identical results. For example, calculated effect sizes for our guilds (using the 27 guilds with adequate sample sizes; Supplementary Table 2) based on the three-point and ordinal scales were strongly, positively and linearly related $\left(F_{1,25}=744.5, R^{2}\right.$ $=96.8 \%, P<0.00001$; least-squares regression analysis).
} 
for this particular variable or indicated that their view was speculative, their response was discarded. Among the experts with good or high confidence, we combined scores to generate a mean value (ranging from -1.0 to 1.0) to estimate the long-term trend in abundance of apex predators at their study site.

The means for all 60 sites were then pooled into a single data distribution (Supplementary Fig. 5). We used bootstrapping (random resampling with replacement; 100,000 iterations) to generate confidence intervals for the overall mean of the data distribution. If the confidence intervals for the mean did not overlap zero, we then interpreted the trend as non-random. Because we tested a number of different guilds, we used a stringent Bonferroni correction $(P=$ 0.0056) to reduce the likelihood of Type I statistical errors. Given that our study has important implications for nature conservation, we also identify guilds that would have shown non-random trends $(P \leq 0.05)$ had we tested them individually.

Supplementary Figure 5 Example of a data distribution for 60 tropical protected areas (arbitrarily divided into increments of 0.4 ), for plotting changes in the abundance of apex predators. The horizontal black line shows the $95 \%$ confidence interval for the mean value, and the $P$ indicates the probability of a non-random deviation from zero.

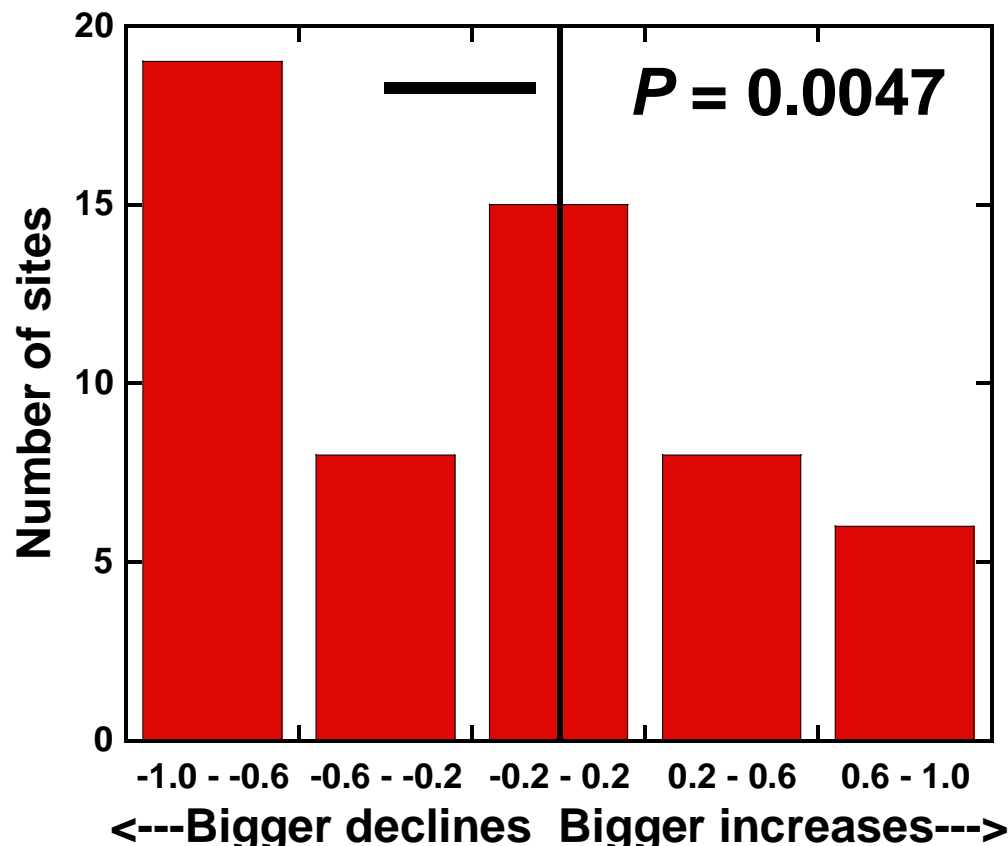

We also assessed effect sizes for changes in guild abundances (Supplementary Table 2) by estimating the mean value for each guild (from bootstrapping), and then dividing this by the standard deviation of that guild. With this procedure, negative values indicate a decline in guild abundance, and positive values an increase. We used a similar procedure to identify changes in our potential environmental driver variables inside (Supplementary Table 3) and outside (Supplementary Table 4) protected areas. 
Our reserve-protection index provided a simple assessment of the degree to which practical, on-the-ground enforcement measures_resulting broadly from the number of park guards and their associated infrastructure, vehicles, supporting legal framework, and level of professional motivation — had changed over the past 20-30 years inside the protected area. Each researcher was asked whether the level of actual protection in their reserve had improved, remained constant, or declined over time (scored as $+1,0$, and -1 , respectively), and the mean value was calculated for each reserve.

We relied on bivariate tests to assess relationships between potential environmental drivers and our reserve-health index. Multivariate analyses were not possible because, for some reserves, data were unavailable for some response variables and drivers. These missing values varied among the reserves, making it impossible to create a complete matrix of drivers and response variables needed for multivariate analyses. We used Spearman rank correlations (with Bonferroni corrections to limit the likelihood of spurious correlations, using a recommended experiment-wise error rate of 0.15 in all cases ${ }^{7}$ ) to identify potential relationships between the drivers and reserve health, and general linear models to test the efficacy of predictors. We evaluated our general linear models using Akaike's information criterion corrected for finite samples $\left(\mathrm{AIC}_{c}\right)$, an information-theoretic index of bias-corrected model weight ${ }^{8}$. We assessed each model's probability using $\mathrm{AIC}_{c}$ weights $\left(w \mathrm{AIC}_{c}\right)$; the closer to 1 , the stronger the relative evidence for that model. The percent deviance explained (\%DE) measures the models' structural goodness-of-fit. The evidence ratio (ER) is the ratio of the $w \mathrm{AIC}_{c}$ for each model over its null (intercept-only model); models with higher ER values have greater support relative to the null.

\section{Validation of interview data}

We explored several strategies for independently testing our interview data. For example, we repeatedly attempted to access time-series data on the abundances of selected vertebrate species being compiled for the Living Planet Index (http://en.wikipedia.org/wiki/Living_Planet_Index), an initiative of WWF and the Zoological Society of London. However, the datasets in this index, at least for the 60 protected areas in our study, are currently too sparse and preliminary to provide a sound basis for comparison (B. Collen, pers. comm.). We also explored data on investments in the management of Amazonian protected areas, but found little usable overlap with our study sites (C. A. Peres, pers. comm.). We did find more overlap between our study sites and a pantropical assessment of fire incidence in and around protected areas ${ }^{9}$, but this study provided only a single estimate of fire frequency, not a time series, and so could not be used to test the trend data from our investigation.

We finally elected to do an extensive meta-analysis of available time-series studies, using data from published or in-press research articles, refereed book chapters, and technical research reports. We established four a priori criteria to include studies. They had to (1) focus on one of the 60 protected areas in our study, (2) yield clearly interpretable data on one of the guilds or potential driver variables we evaluated, (3) provide a time-series of measurements that overlapped at least partially with our study period (the last 20-30 years), and (4) have been published recently, ideally after 2009. This final criterion was designed to limit the exposure of our experts to the scientific work in question (about $85 \%$ of our interviews were conducted between mid 2008 and late 2009), thereby providing a more independent test of our findings. We used several strategies, including the internet, searches of our own extensive technical-literature databases $^{10}$, consultation with other relevant experts, and personal knowledge, to identify potentially suitable time-series. 
We identified 59 independent datasets that met our four selection criteria and provided a direct basis for comparison with our interviews (Supplementary Table 1). These studies used a variety of repeated-sampling approaches, such as mark-recapture studies, track counts, automatic-camera censuses, plot-based monitoring, and remote sensing, to assess temporal changes in their response variables. The datasets, which span 27 different protected areas, are approximately evenly distributed across the three major tropical regions (21 in Africa, 20 in the Americas, 16 in the Asia-Pacific). Nearly half of these studies (28 of 59) focused on one of six well-studied guilds (primates, large non-predatory vertebrates, top predators) or potential driver variables (forest cover inside reserves, forest cover outside reserves, hunting inside reserves), but the remainder were diverse in nature. Altogether, 15 guilds and 13 driver variables were represented by at least one independent dataset.

To provide a direct basis for comparison with our study, we used a simple three-way system (increase, no significant change, decrease) to classify the trend in each independent dataset, following the conclusions of the original researchers. Using this approach, the null hypothesis is that one third of the 59 independent datasets would agree with the trends in our interview data, based simply on chance. We found, however, that the independent datasets agreed with our findings in 51 of the 59 comparisons (86.4\%). This number is strikingly higher than that from random expectation $\left(G_{\mathrm{adj}}=36.50\right.$, d.f. $=1, P<0.0001$; $G$-test for goodness of fit, adjusted for sample size).

In assessing the eight datasets that disagreed with our findings (Supplementary Table 1), we discerned only one obvious pattern: four described trends that occurred recently, and thus might not have been known to the experts we interviewed, or were regarded as not being representative of longer-term trends. For example, one involved recent chytrid-fungus-related declines of stream-dwelling amphibians at Manu National Park in Peru ${ }^{11}$ that were detected only in 2009. Two others resulted from recent (2005-2009) efforts to improve protection of Lope Reserve, Gabon, which have led to a recent increase there in the abundance of elephants and other large non-predatory vertebrates ${ }^{12}$.

Notably, none of the eight disagreements was fundamental in nature-our experts never reported a trend opposite to that shown by the independent test. For example, in Budongo Forest, Uganda, our experts collectively indicated that primate abundance had increased somewhat over the last 2-3 decades, whereas standardized field-monitoring data (35 transects of $2 \mathrm{~km}$ in length that were repeatedly censused from 1992-2009) revealed that individual species abundances varied considerably over time, with no clear trend in overall abundance ${ }^{13}$. Similarly, our experts reported that ambient temperature had increased over time at Los Tuxtlas Biosphere Reserve in Mexico, whereas an independent analysis based on long-term records (1925-2006) from 24 nearby meteorological stations revealed just a slight rise in mean temperature $\left(0.016^{\circ} \mathrm{C}\right.$ per decade) that was not statistically significant ${ }^{14}$.

Overall, these validation tests give us considerable confidence in the efficacy of our interview data (see refs. 15-17 for relevant discussions). The available comparisons do not span all of the protected areas, guilds, or potential driver variables we assessed evenly, but this simply illustrates the highly sparse and patchy nature of suitable time-series analyses. Indeed, the 59 datasets we compiled after extensive efforts represent just a tiny fraction (1.6\%) of the 3,589 assessments of trends in guilds and potential drivers captured by our interview data (our interviews provided 1,262 assessments of guild trends and 2,327 assessments of trends in environmental drivers, across our network of 60 protected areas). It was precisely this deficit that prompted us to undertake this interview-based investigation, to provide a much more systematic 
and far-reaching comparison of the fate of tropical protected areas than has previously been possible.

\section{References}

1. Nelson, A. Estimated Travel Time to the Nearest City of 50,000 or More People in Year 2000 (Global Environment Monitoring Unit, Ispra, Italy; http://bioval.jrc.ec.europa/products/gam, 2008).

2. Groves, R. M. et al., Survey Methodology (John Wiley \& Sons, New York, 2004).

3. GAO, Using Structured Interviewing Techniques (U.S. General Accounting Office, 1991; available at www.gao.gov/special.pubs/pe1015.pdf).

4. Bhagwat, S. et al. Parks and factors in their success. Science 293, 1045-1047 (2001).

5. Korn, E. L. \& Graubard, B. I. Analysis of large health surveys: accounting for the sampling design. J. Roy. Statist. Soc. A 158, 263-295 (1995).

6. Stevens, S. S. On the theory of scales of measurement. Science 103, 677-680 (1946).

7. Chandler, C. R. Practical considerations in the use of simultaneous inference for multiple tests. Anim. Behav. 49, 524-527 (1995).

8. Burnham, K. P. \& Anderson, D. R. Model Selection and Multimodel Inference: A Practical Information-Theoretic Approach (Springer-Verlag, New York, 2002).

9. Wright, S. J., Sanchez-Azofeifa, A., Portillo-Quintero, C. \& Davies, D. Poverty and corruption compromise tropical forest reserves. Ecol. Applic. 17, 1259-1266 (2007).

10. Gibson, L. et al. Primary forests are irreplaceable for sustaining tropical biodiversity. Nature 478, 378-381 (2011).

11. Catenazzi, A., Lehr, E., Rodriguez, L. O. \& Vredenberg, V. T. Batrachochytrium dendrobatidis and the collapse of anuran species richness and abundance in the Upper Manu National Park, Southeastern Peru. Conserv. Biol. 25, 382-391 (2010).

12. Bezangoye, A. \& Maisels, F. Great Ape and Human Impact Monitoring in the Lopé-Waka Exceptional Priority Area, Gabon. Part 1: Lope National Park (GACF Agreement: 98210-8G529, Wildlife Conservation Society, 2010).

13. Babweteera, F. et al. Environmental and anthropogenic changes in and around Budongo Forest Reserve, in Long-term Changes in Africa's Rift Valley: Impacts on Biodiversity and Ecosystems (Ed. A. Plumptre)(Nova Science Publishers, New York, 2012).

14. Gutierrez Garcia, G. \& Ricker, M. Climate and climate change in the region of Los Tuxtlas (Veracruz, Mexico): A statistical analysis. Atmosfera 24, 347-373 (2011).

15. Burgman, M. A. Flaws in subjective assessments of ecological risks and means for correcting them. Aust. J. Environ. Manage. 8, 219-226 (2001).

16. Hockings, M. et al. Data credibility — what are the "right" data for evaluating management effectiveness of protected areas? New Dir. Eval. 122, 53-63 (2009).

17. Cook, C. N. Validating the Use of Expert Opinion in Management Effectiveness Assessments of Protected Areas in Australia (Ph.D. thesis, University of Queensland, Australia, 2010). 
Supplementary Table 1. Independent tests of identified trends in guild abundances and potential environmental drivers from expert interviews, using available time-series data from scientific publications and technical reports. For each test, we indicate whether or not the independent data validated the overall trend identified by our expert interviews. 'Time interval' indicates the span of years covered by each empirical dataset. References for each test are listed below.

\begin{tabular}{|c|c|c|c|c|c|c|}
\hline No. & Protected area & Region & $\begin{array}{l}\text { Guild or driver } \\
\text { trend based on } \\
\text { interviews }\end{array}$ & $\begin{array}{l}\text { Trend } \\
\text { validated? }\end{array}$ & $\begin{array}{l}\text { Time } \\
\text { interval }\end{array}$ & Reference \\
\hline 1 & Budongo & Africa & $\begin{array}{l}\text { Primates increased in } \\
\text { abundance }\end{array}$ & No & $\begin{array}{l}1992- \\
2009\end{array}$ & 1 \\
\hline 2 & Bwindi & Africa & $\begin{array}{l}\text { Harvests of NTFPs } \\
\text { declined inside park }\end{array}$ & Yes & $\begin{array}{l}1991- \\
2003\end{array}$ & 2 \\
\hline 3 & Kakamega & Africa & $\begin{array}{l}\text { Primates increased in } \\
\text { abundance }\end{array}$ & Yes & $\begin{array}{l}1997- \\
2010\end{array}$ & 3,4 \\
\hline 4 & Kakamega & Africa & $\begin{array}{l}\text { Understory birds } \\
\text { declined in } \\
\text { abundance }\end{array}$ & Yes & $\begin{array}{l}1912- \\
2003\end{array}$ & 5 \\
\hline 5 & Kakamega & Africa & $\begin{array}{l}\text { Forest cover declined } \\
\text { inside reserve }\end{array}$ & Yes & $\begin{array}{l}1912- \\
2003\end{array}$ & 5 \\
\hline 6 & Kahuzi-Biega & Africa & $\begin{array}{l}\text { Primates declined in } \\
\text { abundance }\end{array}$ & Yes & $\begin{array}{l}1978- \\
2004\end{array}$ & 6 \\
\hline 7 & Kibale & Africa & $\begin{array}{l}\text { Primates declined in } \\
\text { abundance }\end{array}$ & No & $\begin{array}{l}1975- \\
2006\end{array}$ & 7 \\
\hline 8 & Kibale & Africa & $\begin{array}{l}\text { Ambient temperature } \\
\text { increased inside } \\
\text { reserve }\end{array}$ & Yes & $\begin{array}{l}1975- \\
2006\end{array}$ & 8 \\
\hline 9 & Kibale & Africa & $\begin{array}{l}\text { Rainfall increased } \\
\text { inside reserve }\end{array}$ & Yes & $\begin{array}{l}1900- \\
2006\end{array}$ & 8 \\
\hline 10 & Kilum-Ijim & Africa & $\begin{array}{l}\text { Large-seeded old- } \\
\text { growth trees declined } \\
\text { in abundance }\end{array}$ & Yes & $\begin{array}{l}1998- \\
2006\end{array}$ & 9 \\
\hline 11 & Kilum-Ijim & Africa & $\begin{array}{l}\text { Harvests of NTFPs } \\
\text { increased inside } \\
\text { reserve }\end{array}$ & Yes & $\begin{array}{l}1998- \\
2006\end{array}$ & 9 \\
\hline 12 & Lope & Africa & $\begin{array}{l}\text { Large non-predatory } \\
\text { vertebrates declined }\end{array}$ & No & $\begin{array}{l}2005- \\
2009\end{array}$ & 10 \\
\hline 13 & Lope & Africa & $\begin{array}{l}\text { Hunting increased } \\
\text { inside reserve }\end{array}$ & No & $\begin{array}{l}2005- \\
2009\end{array}$ & 10 \\
\hline 14 & Nouabale-Ndoki & Africa & $\begin{array}{l}\text { Large non-predatory } \\
\text { vertebrates declined }\end{array}$ & Yes & $\begin{array}{l}2006- \\
2011\end{array}$ & 11 \\
\hline 15 & Nouable-Ndoki & Africa & $\begin{array}{l}\text { Hunting increased } \\
\text { inside reserve }\end{array}$ & Yes & $\begin{array}{l}2006- \\
2011\end{array}$ & 11 \\
\hline
\end{tabular}




\begin{tabular}{|c|c|c|c|c|c|c|}
\hline 16 & Nouable-Ndoki & Africa & $\begin{array}{l}\text { Hunting increased } \\
\text { outside reserve }\end{array}$ & Yes & $\begin{array}{l}2006- \\
2011\end{array}$ & 12 \\
\hline 17 & Ngungwe & Africa & $\begin{array}{l}\text { Human populations } \\
\text { increased outside } \\
\text { reserve }\end{array}$ & Yes & $\begin{array}{l}1991- \\
2007\end{array}$ & 13 \\
\hline 18 & Okapi & Africa & $\begin{array}{l}\text { Large non-predatory } \\
\text { vertebrates declined } \\
\text { in abundance }\end{array}$ & Yes & $\begin{array}{l}1995- \\
2006\end{array}$ & 14 \\
\hline 19 & Udzungwa & Africa & $\begin{array}{l}\text { Primates increased in } \\
\text { abundance }\end{array}$ & No & $\begin{array}{l}2004- \\
2009\end{array}$ & 15 \\
\hline 20 & Udzungwa & Africa & $\begin{array}{l}\text { Pioneer/generalist } \\
\text { trees were stable in } \\
\text { abundance }\end{array}$ & Yes & $\begin{array}{l}1986- \\
2007\end{array}$ & 16 \\
\hline 21 & Udzungwa & Africa & $\begin{array}{l}\text { Large-seeded old- } \\
\text { growth trees were } \\
\text { stable in abundance }\end{array}$ & Yes & $\begin{array}{l}1986- \\
2007\end{array}$ & 17 \\
\hline 22 & Udzungwa & Africa & $\begin{array}{l}\text { Forest cover } \\
\text { remained stable } \\
\text { inside the reserve }\end{array}$ & Yes & $\begin{array}{l}1983- \\
2009\end{array}$ & 17 \\
\hline 23 & Udzungwa & Africa & $\begin{array}{l}\text { Forest cover declined } \\
\text { outside reserve }\end{array}$ & Yes & $\begin{array}{l}1983- \\
2009\end{array}$ & 17 \\
\hline 24 & $\begin{array}{l}\text { Barro Colorado } \\
\text { Island }\end{array}$ & Americas & $\begin{array}{l}\text { Lianas increased in } \\
\text { abundance }\end{array}$ & Yes & $\begin{array}{l}1995- \\
2007\end{array}$ & 18 \\
\hline 25 & Brownsberg & Americas & $\begin{array}{l}\text { Illegal mining } \\
\text { increased inside } \\
\text { reserve }\end{array}$ & Yes & $\begin{array}{l}\text { 1971- } \\
2005\end{array}$ & 19 \\
\hline 26 & $\begin{array}{l}\text { Chamela- } \\
\text { Cuixmala }\end{array}$ & Americas & $\begin{array}{l}\text { Top predators } \\
\text { declined in } \\
\text { abundance }\end{array}$ & No & $\begin{array}{l}1995- \\
2008\end{array}$ & 20 \\
\hline 27 & La Selva & Americas & $\begin{array}{l}\text { Terrestrial } \\
\text { amphibians declined } \\
\text { in abundance }\end{array}$ & Yes & $\begin{array}{l}1970- \\
2005\end{array}$ & 21 \\
\hline 28 & La Selva & Americas & $\begin{array}{l}\text { Terrestrial } \\
\text { lizards/larger reptiles } \\
\text { declined in } \\
\text { abundance }\end{array}$ & Yes & $\begin{array}{l}1970- \\
2005\end{array}$ & 21 \\
\hline 29 & La Selva & Americas & $\begin{array}{l}\text { Understory } \\
\text { insectivorous birds } \\
\text { declined in } \\
\text { abundance }\end{array}$ & Yes & $\begin{array}{l}1960- \\
1999\end{array}$ & 22 \\
\hline 30 & Los Amigos & Americas & $\begin{array}{l}\text { Top predators } \\
\text { increased in } \\
\text { abundance }\end{array}$ & Yes & $\begin{array}{l}2004- \\
2008\end{array}$ & 23 \\
\hline 31 & Los Amigos & Americas & $\begin{array}{l}\text { Large non-predatory } \\
\text { vertebrates increased } \\
\text { in abundance }\end{array}$ & Yes & $\begin{array}{l}2004- \\
2008\end{array}$ & 23 \\
\hline
\end{tabular}




\begin{tabular}{|c|c|c|c|c|c|c|}
\hline 32 & Los Amigos & Americas & $\begin{array}{l}\text { Primates increased in } \\
\text { abundance }\end{array}$ & Yes & $\begin{array}{l}2004- \\
2008\end{array}$ & 23 \\
\hline 33 & Los Amigos & Americas & $\begin{array}{l}\text { Omnivorous } \\
\text { mammals increased } \\
\text { in abundance }\end{array}$ & Yes & $\begin{array}{l}2004- \\
2008\end{array}$ & 23 \\
\hline 34 & Los Amigos & Americas & $\begin{array}{l}\text { Game birds increased } \\
\text { in abundance }\end{array}$ & Yes & $\begin{array}{l}2004- \\
2008\end{array}$ & 23 \\
\hline 35 & Los Amigos & Americas & $\begin{array}{l}\text { Larger frugivorous } \\
\text { birds increased in } \\
\text { abundance }\end{array}$ & Yes & $\begin{array}{l}2004- \\
2008\end{array}$ & 23 \\
\hline 36 & Los Amigos & Americas & $\begin{array}{l}\text { Hunting declined } \\
\text { inside reserve }\end{array}$ & Yes & $\begin{array}{l}2004- \\
2008\end{array}$ & 23 \\
\hline 37 & Los Amigos & Americas & $\begin{array}{l}\text { Forest cover declined } \\
\text { outside reserve }\end{array}$ & Yes & $\begin{array}{l}2002- \\
2010\end{array}$ & 23 \\
\hline 38 & Los Amigos & Americas & $\begin{array}{l}\text { Illegal mining } \\
\text { increased outside } \\
\text { reserve }\end{array}$ & Yes & $\begin{array}{l}2002- \\
2010\end{array}$ & 24 \\
\hline 39 & Los Tuxtlas & Americas & $\begin{array}{l}\text { Ambient temperature } \\
\text { increased inside } \\
\text { reserve }\end{array}$ & No & $\begin{array}{l}1925- \\
2006\end{array}$ & 25 \\
\hline 40 & Luquillo & Americas & $\begin{array}{l}\text { Exotic plants } \\
\text { increased in } \\
\text { abundance }\end{array}$ & Yes & $\begin{array}{l}1936- \\
2003\end{array}$ & 26 \\
\hline 41 & Manu & Americas & $\begin{array}{l}\text { No change in stream- } \\
\text { dwelling amphibian } \\
\text { abundance }\end{array}$ & No & $\begin{array}{l}1999- \\
2009\end{array}$ & 27 \\
\hline 42 & Manu & Americas & $\begin{array}{l}\text { No change in } \\
\text { terrestrial amphibian } \\
\text { abundance }\end{array}$ & Yes & $\begin{array}{l}1999- \\
2009\end{array}$ & 27 \\
\hline 43 & Nouragues & Americas & $\begin{array}{l}\text { Illegal mining } \\
\text { increased inside } \\
\text { reserve }\end{array}$ & Yes & $\begin{array}{l}2000- \\
2008\end{array}$ & 28 \\
\hline 44 & Anamalai & $\begin{array}{l}\text { Asia- } \\
\text { Pacific }\end{array}$ & $\begin{array}{l}\text { Primates increased in } \\
\text { abundance }\end{array}$ & Yes & $\begin{array}{l}1996- \\
2010\end{array}$ & 29 \\
\hline 45 & Khao Yai & $\begin{array}{l}\text { Asia- } \\
\text { Pacific }\end{array}$ & $\begin{array}{l}\text { Top predators } \\
\text { declined in } \\
\text { abundance }\end{array}$ & Yes & $\begin{array}{l}1999- \\
2007\end{array}$ & 30 \\
\hline 46 & Lambir & $\begin{array}{l}\text { Asia- } \\
\text { Pacific }\end{array}$ & $\begin{array}{l}\text { Large non-predatory } \\
\text { vertebrates declined } \\
\text { in abundance }\end{array}$ & Yes & $\begin{array}{l}1984- \\
2007\end{array}$ & 31 \\
\hline 47 & Lambir & $\begin{array}{l}\text { Asia- } \\
\text { Pacific }\end{array}$ & $\begin{array}{l}\text { Primates declined in } \\
\text { abundance }\end{array}$ & Yes & $\begin{array}{l}1984- \\
2007\end{array}$ & 31 \\
\hline 48 & Lambir & $\begin{array}{l}\text { Asia- } \\
\text { Pacific }\end{array}$ & $\begin{array}{l}\text { Omnivorous } \\
\text { mammals declined in } \\
\text { abundance }\end{array}$ & Yes & $\begin{array}{l}1984- \\
2007\end{array}$ & 31 \\
\hline
\end{tabular}




\begin{tabular}{|l|l|l|l|l|l|l|}
\hline 49 & Lambir & $\begin{array}{l}\text { Asia- } \\
\text { Pacific }\end{array}$ & $\begin{array}{l}\text { Larger frugivorous } \\
\text { birds declined in } \\
\text { abundance }\end{array}$ & Yes & $\begin{array}{l}1984- \\
2007\end{array}$ & 31 \\
\hline 50 & Lambir & $\begin{array}{l}\text { Asia- } \\
\text { Pacific }\end{array}$ & $\begin{array}{l}\text { Raptorial birds } \\
\text { declined in } \\
\text { abundance }\end{array}$ & Yes & $\begin{array}{l}1984- \\
2007\end{array}$ & 31 \\
\hline 51 & Lambir & $\begin{array}{l}\text { Asia- } \\
\text { Pacific }\end{array}$ & $\begin{array}{l}\text { Hunting increased } \\
\text { inside reserve }\end{array}$ & Yes & $\begin{array}{l}1984- \\
2007\end{array}$ & 31 \\
\hline 52 & Lore Lindu & $\begin{array}{l}\text { Asia- } \\
\text { Pacific }\end{array}$ & $\begin{array}{l}\text { Forest cover declined } \\
\text { inside reserve }\end{array}$ & Yes & $\begin{array}{l}1972- \\
2007\end{array}$ & 32 \\
\hline 53 & $\begin{array}{l}\text { Mudumalai- } \\
\text { Bandipur }\end{array}$ & $\begin{array}{l}\text { Asia- } \\
\text { Pacific }\end{array}$ & $\begin{array}{l}\text { Exotic plants } \\
\text { increased in reserve }\end{array}$ & Yes & $\begin{array}{l}1997- \\
2008\end{array}$ & 33 \\
\hline 54 & Mudumalai- & $\begin{array}{l}\text { Asia- } \\
\text { Pacific }\end{array}$ & $\begin{array}{l}\text { Fires increased inside } \\
\text { reserve }\end{array}$ & Yes & $\begin{array}{l}1989- \\
2005\end{array}$ & 34 \\
\hline 55 & $\begin{array}{l}\text { Northern Sierra } \\
\text { Madre }\end{array}$ & $\begin{array}{l}\text { Asia- } \\
\text { Pacific }\end{array}$ & $\begin{array}{l}\text { Forest cover declined } \\
\text { inside reserve }\end{array}$ & Yes & $\begin{array}{l}1972- \\
2002\end{array}$ & 35 \\
\hline 56 & $\begin{array}{l}\text { Northern Sierra } \\
\text { Madre }\end{array}$ & $\begin{array}{l}\text { Asia- } \\
\text { Pacific }\end{array}$ & $\begin{array}{l}\text { Forest cover declined } \\
\text { outside reserve }\end{array}$ & Yes & $\begin{array}{l}1972- \\
2002\end{array}$ & 35 \\
\hline 57 & $\begin{array}{l}\text { Northern Sierra } \\
\text { Madre }\end{array}$ & $\begin{array}{l}\text { Asia- } \\
\text { Pacific }\end{array}$ & $\begin{array}{l}\text { Logging increased } \\
\text { inside reserve }\end{array}$ & Yes & $\begin{array}{l}2003- \\
2009\end{array}$ & 36 \\
\hline 58 & Xishuangbanna & $\begin{array}{l}\text { Asia- } \\
\text { Pacific }\end{array}$ & $\begin{array}{l}\text { Forest cover declined } \\
\text { outside reserve }\end{array}$ & Yes & $\begin{array}{l}1976- \\
2003\end{array}$ & 37 \\
\hline 59 & Xishuangbannna & $\begin{array}{l}\text { Asia- } \\
\text { Pacific }\end{array}$ & $\begin{array}{l}\text { Exotic tree } \\
\text { plantations increased } \\
\text { around reserve }\end{array}$ & Yes & $\begin{array}{l}1976- \\
2003\end{array}$ & 37 \\
& & & & & \\
\hline
\end{tabular}

\section{References: Supplementary Table 1}

1. Babweteera, F. et al. Environmental and anthropogenic changes in and around Budongo Forest Reserve, in Long-term Changes in Africa's Rift Valley: Impacts on Biodiversity and Ecosystems (Ed. A. Plumptre)(Nova Science Publishers, New York, 2012).

2. Olupot, W., Barigyira, R. \& Chapman, C. A. The status of anthropogenic threat at the people-park interface of Bwindi Impenetrable National Park, Uganda. Environ. Conserv. 36, 41-50 (2009).

3. Fashing, P. J. \& Cords, M. Diurnal primate densities and biomass in the Kakamega Forest: An evaluation of census methods and a comparison with other forests. Amer. J. Primatol. 50, 139-152 (2000).

4. Fashing, P. J. et al. Evaluating the suitability of planted forests for African forest monkeys: A case study from Kakamega Forest, Kenya. Amer. J. Primatol. 74, 77-90 (2012).

5. Lung, T. et al. Combining long-term land cover time series and field observations for spatially explicit predictions on changes in tropical forest biodiversity. Intern. J. Remote Sensing 33, 13-40 (2012).

6. Yamagiwa, J. et al. Long-term changes in habitats and ecology of African apes in KahuziBiega National Park, Democratic Republic of Congo, in Long-term Changes in Africa's Rift Valley: Impacts on Biodiversity and Ecosystems (Ed. A. Plumptre)(Nova Science Publishers, New York, 2012). 
7. Chapman, C. A. et al. Understanding long-term primate community dynamics: Implications of forest change. Ecol. Applic. 20, 179-191 (2010a).

8. Chapman, C. A. et al. Tropical tree community shifts: Implications for wildlife conservation. Biol. Conserv. 143, 366-374 (2010b).

9. Stewart, K. Effects of bark harvest and other human activity on populations of the African cherry (Prunus africana) on Mount Oku, Cameroon. Forest Ecol. Mgmt. 258, 1121-1128 (2009).

10. Bezangoye, A. \& Maisels, F. Great Ape and Human Impact Monitoring in the Lopé-Waka Exceptional Priority Area, Gabon. Part 1: Lope National Park (GACF Agreement: 98210-8G529, Wildlife Conservation Society, 2010).

11. Maisels, F. et al. Great Ape and Human Impact Monitoring, Training, Surveys, and Protection in the Ndoki-Likouala Landscape, Republic of Congo (GACF Agreement: 96200-9-G247, Final report, Wildlife Conservation Society, 2012).

12. Nishihara, T. Law Enforcement Efforts-Nouabale-Ndoki National Park and Periphery Zones, Northern Congo, December 2010-April 2011 (Wildlife Conservation Society-Congo, 2011).

13. Chao, N. et al. Long term changes in a montane forest in a region of high human population density, in Long-term Changes in Africa's Rift Valley: Impacts on Biodiversity and Ecosystems (Ed. A. Plumptre)(Nova Science Publishers, New York, 2012).

14. Beyers, R. L. et al. Resource wars and conflict ivory: The impact of civil war on elephants in the Democratic Republic of Congo-The case of Okapi Reserve. PLoS One 6, e27129. doi:10.1371/journal.pone.0027129.

15. Rovero, F., Mtui, A. S., Kitegile, A. \& Nielsen, M. R. Hunting or habitat degradation? Decline of primate populations in Udzungaw Mountains, Tanzania: An analysis of threats. Biol. Conserv. 146, 89-96 (2012).

16. Marshall, A. R. et al. Measuring and modelling above-ground live carbon storage and tree allometry along a tropical elevation gradient. Biol. Conserv. (in press).

17. Marshall, A.R. et al. The species-area relationship and confounding variables in a threatened monkey community. Amer. J. Primatol. 72, 325-336 (2010).

18. Ingwell, L. L. et al. The impact of lianas on 10 years of tree growth and mortality on Barro Colorado Island, Panama. J. Ecol. 98, 879-887 (2010).

19. Hammond, D. S. et al. Causes and consequences of a tropical forest gold rush in the Guiana Shield, South America. Ambio 36, 661-670 (2007).

20. Núñez-Pérez, R. Estimating jaguar population density using camera-traps: a comparison with radio-telemetry estimates. J. Zool. 285, 39-45 (2011).

21. Whitfield, S. M. et al. Amphibian and reptile declines over 35 years at La Selva, Costa Rica. Proc. Nat. Acad. Sci. USA 104, 8532-8536 (2007).

22. Sigel, B. J., Sherry, T. W. \& Young, B. E. Avian community response to lowland rainforest isolation: 40 years of change at La Selva Biological Station, Costa Rica. Conserv. Biol. 20, 111-121 (2006).

23. Pitman, N. C. A. et al. Four years of vertebrate monitoring on an upper Amazonian river. Biodiv. Conserv. 20, 827-849 (2011).

24. Swenson, J. J., Carter, C. E. Domec, J.-C. \& Delgado, C. Gold mining in the Peruvian Amazon: Global prices, deforestation, and mercury imports. PLoS One 6, e18875. doi:10.1371/journal.pone.0018875 (2011). 
25. Gutierrez Garcia, G. \& Ricker, M. Climate and climate change in the region of Los Tuxtlas (Veracruz, Mexico): A statistical analysis. Atmosfera 24, 347-373 (2011).

26. Brown, K. A., Scatena, F. N. \& Gurevitch, J. Effects of an invasive tree on community structure and diversity in a tropical forest in Puerto Rico. Forest Ecol. Manage. 226, 145152 (2006).

27. Catenazzi, A., Lehr, E., Rodriguez, L. O. \& Vredenberg, V. T. Batrachochytrium dendrobatidis and the collapse of anuran species richness and abundance in the Upper Manu National Park, Southeastern Peru. Conserv. Biol. 25, 382-391 (2010).

28. WWF-Guyane. Les Impacts Environnementaux liés à l'Exploitation Aurifère dans la Région des Guyanes (www.une-saison-en-guyane.com/article/ecologie/les-impactsenvironnementaux-lies-a-1\%E2\%80\%99exploitation-aurifere-ont-ete-multiplies-par-troisen-sept-ans-dans-la-region-des-guyanes/m, 2010).

29. Umapathy, G., Hussain, S. \& Shivaji, S. Impact of habitat fragmentation on the demography of lion-tailed macaque (Macaca silenus) populations in the rainforests of Anamalai Hills, Western Ghats, India. Int. J. Primatol. 32, 889-900 (2011).

30. Jenks, K. E. et al. Using relative abundance indices from camera-trapping to test wildlife conservation hypotheses - an example from Khao Mai National Park, Thailand. Trop. Conserv. Sci. 4, 113-131 (2011).

31. Harrison, R. D. Emptying the forest: Hunting and the extirpation of wildlife from tropical nature reserves. BioScience 61, 919-924 (2011).

32. Mehring, M. \& Stoll-Kleemann, S. How effective is the buffer zone? Linking institutional processes with satellite images from a case study in the Lore Lindu Biosphere Reserve, Indonesia. Ecology \& Society 16(4), 3. doi:10.5751/ES-04349-160403 (2011).

33. Sundaram, B. \& Hiremath, A. J. Lantana camara invasion in a heterogeneous landscape: Patterns of spread and correlation with changes in native vegetation. Biol. Invasions, DOI 10.1007/s10530-011-0144-2 (2011).

34. Kodandapani, N., M. A. Cochrane \& Sukumar, R. Forest fire regimes and their ecological effects in seasonally dry tropical ecosystems in the Western Ghats, India. Pp. 335-354 in Cochrane, M. A. (Ed.), Tropical Fire Ecology: Climate change, Land use and Ecosystem Dynamics (Springer-Praxis, Heidelberg, Germany, 2009).

35. Verburg, P. H. et al. Analysis of the effects of land use change on protected areas in the Philippines. Appl. Geogr. 26, 153-173 (2006).

36. van der Ploeg, J., van Weerd, M., Masipequeña, A. \& Persoon, G. Illegal logging in the Sierra Madre Natural Park, the Philippines. Conserv. Society 9, 202-215 (2011).

37. Li, H., Ma, Y., Liu, W. \& Liu W. Clearance and fragmentation of tropical rain forest in Xishuangbanna, SW China. Biodiv. Conserv. 18, 3421-3440 (2009). 


\section{Supplementary Analyses}

Supplementary Figure 6 Effects of surrounding disturbances on reserve health (mean \pm SD). Health values declined less in reserves where deforestation, logging or fires were stable or declined, relative to those where these disturbances increased over time. $P$ values shown are for Mann-Whitney $U$-tests. Sample sizes are in parentheses.

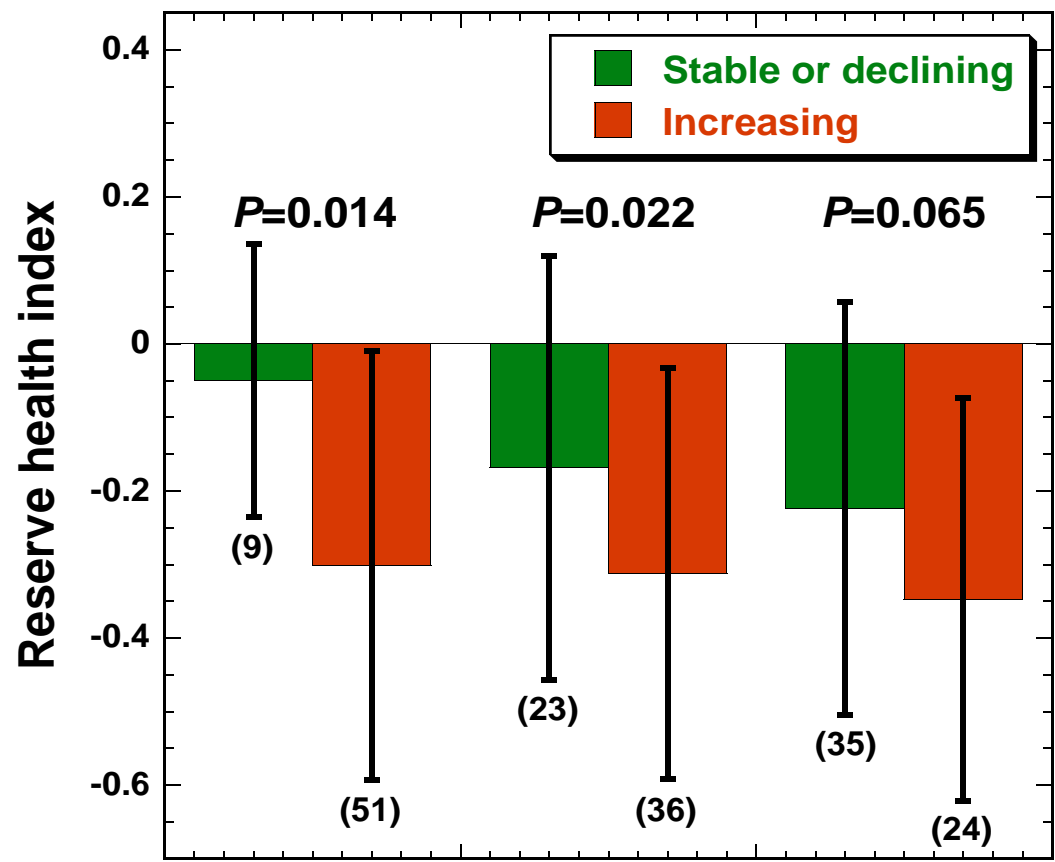

\section{Deforestation Logging Fires}


Supplementary Table 2 Trends in the abundance of 27 animal and plant guilds within 60 tropical protected areas, ranked by effect size (negative values indicate declines in guild abundance, and positive values an increase). $P$ values shown in bold are non-random using a stringent Bonferroni correction $(P \leq 0.0056)$, whereas those in italics are non-random at $P \leq$ 0.05 . The $P$ values, estimated mean, and upper and lower $95 \%$ confidence limits (CLs) for each guild were estimated by bootstrapping (with 100,000 iterations). Four guilds (aquatic invertebrates, army/driver ants, disease-vectoring invertebrates, dung beetles) were too poorly known to reliably assess overall trends in their abundance.

\section{Guild}

Ecological specialists

Stream amphibians

Freshwater fish

Terrestrial amphibians

Non-venomous snakes

Bats

Lizards \& larger reptiles

Venomous snakes

Large non-predatory spp.

Epiphytes

Lg-seed old-growth trees

Spp. requiring tree cavities

Migratory species

Understory insectiv. birds

Apex predators

Raptorial birds

Light-loving butterflies

Larger frugivorous birds

Primates

Rodents

Larger game birds

Opportunistic omnivores

Human diseases

Lianas \& vines

Exotic animal species

Pioneer \& generalist trees

Exotic plant species

\begin{tabular}{|c|c|c|c|c|c|c|}
\hline $\mathbf{P}$ & $\begin{array}{l}\text { Effect } \\
\text { size }\end{array}$ & Mean & SD & $\begin{array}{c}\text { Lower } \\
\text { CL }\end{array}$ & $\begin{array}{l}\text { Upper } \\
\text { CL }\end{array}$ & $\begin{array}{c}\text { No data } \\
\text { (\%) }\end{array}$ \\
\hline$<0.00001$ & -1.053 & -0.425 & 0.4035 & -0.600 & -0.250 & 50.0 \\
\hline 0.00002 & -1.012 & -0.3495 & 0.3452 & -0.525 & -0.17391 & 56.7 \\
\hline$<0.00001$ & -0.893 & -0.4411 & 0.4938 & -0.63441 & -0.24775 & 41.7 \\
\hline 0.00157 & -0.796 & -0.2786 & 0.3497 & -0.45455 & -0.10256 & 53.3 \\
\hline 0.00127 & -0.761 & -0.2968 & 0.3903 & -0.4881 & -0.10556 & 51.7 \\
\hline 0.00190 & -0.666 & -0.1772 & 0.266 & -0.2973 & -0.05714 & 46.7 \\
\hline 0.00382 & -0.564 & -0.2877 & 0.5097 & -0.49495 & -0.08036 & 40.0 \\
\hline 0.01511 & -0.53 & -0.2261 & 0.4263 & -0.42929 & -0.02299 & 48.3 \\
\hline 0.00022 & -0.48 & -0.2871 & 0.5985 & -0.44583 & -0.12845 & 5.0 \\
\hline 0.00557 & -0.439 & -0.151 & 0.3439 & -0.26798 & -0.03398 & 26.7 \\
\hline 0.00086 & -0.436 & -0.2033 & 0.4658 & -0.33041 & -0.0 & 8.3 \\
\hline 0.01852 & -0.389 & -0.1794 & 0.4616 & -0.34804 & -0.01068 & 31.7 \\
\hline 0.04674 & -0.368 & -0.1463 & 0.3973 & -0.31707 & 0.02451 & 41.7 \\
\hline 0.01112 & -0.368 & -0.1482 & 0.4023 & -0.27516 & -0.0 & 20.0 \\
\hline 0.00469 & -0.361 & -0.2151 & 0.5958 & -0.37 & -0.05455 & 6.7 \\
\hline 0.02587 & -0.314 & -0.1385 & 0.4414 & -0.27733 & 0.00043 & 20.0 \\
\hline 0.16 & -0.299 & -0.1082 & 0.3617 & -0.3125 & 0.09615 & 55.0 \\
\hline 0.03055 & -0.276 & -0.1269 & 0.4598 & -0.26042 & 0.00654 & 13.3 \\
\hline 0.02777 & -0.269 & -0.1489 & 0.553 & -0.30121 & 0.00333 & 8.3 \\
\hline 0.13 & -0.188 & -0.0975 & 0.5195 & -0.268 & 64 & 23.3 \\
\hline 0.13 & -0.166 & -0.0884 & 0.5312 & -0.24691 & 0.07 & 15.0 \\
\hline 0.12 & -0.164 & -0.0996 & 0.6067 & -0.27075 & 0.07164 & 10.0 \\
\hline 0.00115 & 0.438 & 0.2288 & 0.5227 & 0.08025 & 0.37727 & 11.7 \\
\hline 0.00116 & 0.467 & 0.2016 & 0.4316 & 0.07516 & 0.32801 & 15.0 \\
\hline$<0.00001$ & 0.904 & 0.3475 & 0.3842 & 0.24214 & 0.45283 & 11.7 \\
\hline$<0.00001$ & 1.028 & 0.4592 & 0.4465 & 0.3366 & 0.5817 & 15.0 \\
\hline$<0.00001$ & 1.169 & 0.4823 & 0.4126 & 0.375 & 0.58951 & 6.7 \\
\hline
\end{tabular}


Supplementary Table 3 As in Supplementary Table 1 except for potential environmental drivers inside protected areas, and with a different Bonferroni correction $(P \leq 0.0071)$.

$\begin{array}{lrrrrrrr}\text { Driver variable } & \mathbf{P} & \text { size } & \text { Mean } & \text { SD } & \text { CI } & \text { CI } & \text { (\%) } \\ \text { Reserve health } & <\mathbf{0 . 0 0 0 0 1} & -0.910 & -0.2313 & 0.2686 & -0.3372 & -0.1879 & 0 \\ \text { River \& stream flows } & 0.01052 & -0.301 & -0.1048 & 0.3484 & -0.1944 & -0.0153 & 1.7 \\ \text { Exotic plantations } & 0.03395 & -0.237 & -0.0486 & 0.2048 & -0.1006 & 0.0033 & 0 \\ \text { Selective logging } & 0.13 & -0.147 & -0.0649 & 0.4399 & -0.1761 & 0.0464 & 0 \\ \text { Natural-forest cover } & 0.25 & -0.085 & -0.0381 & 0.4501 & -0.1519 & 0.0758 & 0 \\ \text { Illegal mining } & 0.35 & -0.047 & -0.0116 & 0.2452 & -0.0750 & 0.0517 & 1.7 \\ \text { Fires } & 0.44 & -0.024 & -0.0076 & 0.3169 & -0.0883 & 0.0731 & 0 \\ \text { Rainfall } & 0.40 & 0.038 & 0.0156 & 0.4085 & -0.0994 & 0.1305 & 10.0 \\ \text { Hunting } & 0.11 & 0.157 & 0.0982 & 0.6249 & -0.0597 & 0.2561 & 0 \\ \text { NTFP harvests } & 0.02816 & 0.247 & 0.1193 & 0.4828 & -0.0031 & 0.2417 & 0 \\ \text { Soil erosion } & <\mathbf{0 . 0 0 0 0 1} & 0.517 & 0.1800 & 0.3483 & 0.0893 & 0.2708 & 3.3 \\ \text { Reserve-protection effort } & \mathbf{0 . 0 0 0 0 5} & 0.520 & 0.2500 & 0.4806 & 0.1286 & 0.3714 & 0 \\ \text { Flooding } & <\mathbf{0 . 0 0 0 0 1} & 0.539 & 0.1489 & 0.2762 & 0.0760 & 0.2217 & 5.0 \\ \text { Windstorms } & <\mathbf{0 . 0 0 0 0 1} & 0.561 & 0.1580 & 0.2819 & 0.0759 & 0.2402 & 15.0 \\ \text { Roads } & <\mathbf{0 . 0 0 0 0 1} & 0.599 & 0.1294 & 0.2160 & 0.0747 & 0.1842 & 0 \\ \text { Stream sedimentation } & <\mathbf{0 . 0 0 0 0 1} & 0.633 & 0.2497 & 0.3945 & 0.1404 & 0.3591 & 10.0 \\ \text { Human population density } & <\mathbf{0 . 0 0 0 0 1} & 0.668 & 0.2286 & 0.3425 & 0.1417 & 0.3156 & 0 \\ \text { Water pollution } & <\mathbf{0 . 0 0 0 0 1} & 0.709 & 0.2205 & 0.3111 & 0.1396 & 0.3014 & 3.3 \\ \text { Ambient temperature } & <\mathbf{0 . 0 0 0 0 1} & 0.745 & 0.2687 & 0.3609 & 0.1633 & 0.3742 & 16.7 \\ \text { Livestock grazing } & <\mathbf{0 . 0 0 0 0 1} & 0.765 & 0.2233 & 0.2919 & 0.1497 & 0.2969 & 0 \\ \text { Drought severity/intensity } & <\mathbf{0 . 0 0 0 0 1} & 0.851 & 0.3200 & 0.3759 & 0.2218 & 0.4181 & 5.0 \\ \text { Air pollution } & <\mathbf{0 . 0 0 0 0 1} & 0.892 & 0.2946 & 0.3303 & 0.2068 & 0.3824 & 6.7 \\ \text { Automobile traffic } & <\mathbf{0 . 0 0 0 0 1} & 0.906 & 0.2806 & 0.3095 & 0.2022 & 0.3589 & 0\end{array}$


Supplementary Table 4 As in Supplementary Table 1 except for potential environmental drivers outside of protected areas (within a $3 \mathrm{~km}$-wide zone around the protected area), and with a different Bonferroni correction $(P \leq 0.0071)$.

\begin{tabular}{|c|c|c|c|c|c|c|c|}
\hline & $\mathbf{P}$ & $\begin{array}{l}\text { Effect } \\
\text { size }\end{array}$ & Mean & SD & $\begin{array}{c}\text { Lower } \\
\text { CI }\end{array}$ & $\begin{array}{c}\text { Upper } \\
\text { CI }\end{array}$ & $\begin{array}{c}\text { No data } \\
(\%)\end{array}$ \\
\hline Natural-forest cover & $<0.00001$ & -1.470 & -0.5907 & 0.4019 & -0.6925 & -0.489 & 1.7 \\
\hline River \& stream flows & 0.03883 & -0.248 & -0.1005 & 0.4052 & -0.2115 & 0.0106 & 8.3 \\
\hline Rainfall & 0.27 & -0.088 & -0.0337 & 0.3819 & -0.1431 & 0.0756 & 11.7 \\
\hline Fires & 0.00433 & 0.348 & 0.1412 & 0.4054 & 0.0350 & 0.2474 & 3.3 \\
\hline Hunting & 0.00153 & 0.398 & 0.2257 & 0.5674 & 0.0778 & 0.3736 & 3.3 \\
\hline Livestock grazing & 0.00094 & 0.432 & 0.1919 & 0.4442 & 0.0747 & 0.3092 & 5.0 \\
\hline Windstorms & $<0.00001$ & 0.593 & 0.1432 & 0.2417 & 0.0677 & 0.2188 & 21.7 \\
\hline Flooding & $<0.00001$ & 0.605 & 0.2492 & 0.4115 & 0.1358 & 0.3626 & 10.0 \\
\hline Illegal mining & $<0.00001$ & 0.626 & 0.2687 & 0.4295 & 0.1541 & 0.3833 & 6.7 \\
\hline NTFP harvests & $<0.00001$ & 0.720 & 0.3152 & 0.4378 & 0.1927 & 0.4377 & 11.7 \\
\hline Selective logging & $<0.00001$ & 0.729 & 0.3613 & 0.4956 & 0.2325 & 0.4901 & 3.3 \\
\hline Exotic plantations & $<0.00001$ & 0.749 & 0.3416 & 0.4561 & 0.2199 & 0.4633 & 6.7 \\
\hline Ambient temperature & $<0.00001$ & 0.818 & 0.3221 & 0.3940 & 0.2067 & 0.4375 & 18.3 \\
\hline Air pollution & $<0.00001$ & 0.966 & 0.3716 & 0.3846 & 0.2682 & 0.4750 & 10.0 \\
\hline Drought severity/intensity & $<0.00001$ & 0.978 & 0.3747 & 0.3830 & 0.2674 & 0.4820 & 15.0 \\
\hline Water pollution & $<0.00001$ & 1.218 & 0.4936 & 0.4054 & 0.3898 & 0.5975 & 5.0 \\
\hline Stream sedimentation & $<0.00001$ & 1.234 & 0.5417 & 0.4390 & 0.4219 & 0.6616 & 18.3 \\
\hline Soil erosion & $<0.00001$ & 1.356 & 0.5638 & 0.4158 & 0.4576 & 0.6699 & 10.0 \\
\hline Roads & $<0.00001$ & 1.671 & 0.6601 & 0.3950 & 0.5607 & 0.7594 & 1.7 \\
\hline Automobile traffic & $<0.00001$ & 1.845 & 0.7012 & 0.3801 & 0.6078 & 0.7945 & 3.3 \\
\hline Human population density & $<0.00001$ & 2.294 & 0.7943 & 0.3462 & 0.7097 & 0.8789 & 1.7 \\
\hline
\end{tabular}


Supplementary Table 5 Assessing effects of potential environmental drivers on the reservehealth index, using Spearman rank correlations and general linear models (GLMs). For the correlations, $P$ values in bold have a Bonferroni-corrected value of $P \leq 0.0071$. For the GLMs, the strongest models are those with weights of the Akaike's information criterion corrected for sample size $\left(w \mathrm{AIC}_{c}\right)$ that are closest to 1 . The percent deviance explained (\%DE) measures the models' structural goodness-of-fit, whereas models with higher ER values have greater support relative to the null (intercept-only) model. Models with blanks could not be fitted with plausible error structures.

\section{Potential driver}

Natural forest cover-outside

Natural forest cover-inside

Livestock grazing-inside

Automobile traffic-inside

Air pollution-inside

Stream sedimentation-outside

Ambient temperature-inside

Road expansion-outside

Droughts-inside

Illegal mining-outside

Road expansion-inside

Automobile traffic-outside

Windstorms-inside

Rainfall-outside

Windstorms-outside

Rainfall-inside

Ambient temperature-outside

Soil erosion-outside

Illegal mining-inside

Water pollution-inside

Water pollution-outside

Stream sedimentation-inside

Exotic-tree plantations-outside

Livestock grazing-outside

Floods-outside

Stream/river flows-outside

Human populations-inside

Air pollution-outside

Stream/river flows-inside

\section{Correlations}

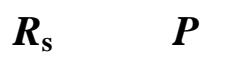

0.487

0.432

0.178

0.15

0.052

0.052

0.046

0.036

0.011

0.003

$-0.017$

$-0.029$

$-0.049$

$-0.054$

$-0.064$

$-0.071$

$-0.086$

$-0.089$

$-0.107$

$-0.111$

$-0.129$

$-0.141$

$-0.143$

$-0.155$

$-0.158$

$-0.164$

$-0.171$

$-0.181$

$-0.19$
0.0001

0.0006

0.174

0.251

0.706

0.722

0.749

0.784

0.937

0.980

0.897

0.829

0.735

0.700

0.667

0.609

0.555

0.520

0.418

0.405

0.335

0.310

0.288

0.246

0.249

0.227

0.190

0.185

0.150

\section{General Linear Models}

wAIC $_{c}$ ER \%DE

$0.989 \quad 85.9 \quad 16.9$

0.998

502.5

21.7

0.786

3.7

0.6

7.7

2.2

13.3

0.842

0.189

5.2

10.3

0.887

0.309

0.529

0.703

0.252

0.224

0.576

0.2

21.2

7.5

0.4

1.1

1.7

0.3

0.3

-----

1.3

12.2

1
7.3

7.5

0.1

0.6

0.825

0.438

0.205

$---$

0.724

0.772

0.579

0.138

0.701

-----

0.183

0.4

0.92

0.757
15.1

4.6

0.7

14.6

0.3

4.5

2.6

8.

3.4

9.7

1.3

11.2

0.2

0.7

2.3

8.5

-----

0.2

2.9

2.3

0.7
11.3

16.8

$3.1 \quad 8.3$ n

59

60

60

60

56

49

50

59

57

56

60

58

51

53

47

54

49

54

59

58

57

54

56

57

54

55

60

54

59 


$\begin{array}{lrrrrrr}\text { Human populations-outside } & -0.202 & 0.122 & 0.654 & 1.9 & 5.7 & 59 \\ \text { Hunting-outside } & -0.205 & 0.119 & 0.777 & 3.5 & 8.7 & 58 \\ \text { Soil erosion-inside } & -0.213 & 0.109 & 0.677 & 2.1 & 8.2 & 58 \\ \text { Exotic-tree plantations-inside } & -0.216 & 0.097 & 0.622 & 1.6 & 5.2 & 60 \\ \text { Drought-outside } & -0.223 & 0.113 & 0.977 & 40.3 & 24 & 51 \\ \text { NTFP harvests-outside } & -0.239 & 0.081 & 0.928 & 12.5 & 18.2 & 53 \\ \text { Floods-inside } & -0.253 & 0.058 & ----- & ----- & ----- & 57 \\ \text { Fires-outside } & -0.279 & 0.0323 & 0.955 & 21.2 & 14.1 & 58 \\ \text { Fires-inside } & -0.288 & 0.0254 & 0.94 & 15.7 & 12.1 & 60 \\ \text { NTFP harvests-inside } & -0.353 & \mathbf{0 . 0 0 5 7} & 0.971 & 33.8 & 14.3 & 60 \\ \text { Selective logging-outside } & -0.373 & \mathbf{0 . 0 0 3 6} & 0.862 & 6.2 & 10.5 & 58 \\ \text { Selective logging-inside } & -0.397 & \mathbf{0 . 0 0 1 7} & 0.973 & 36.1 & 14.5 & 60 \\ \text { Hunting-inside } & -0.452 & \mathbf{0 . 0 0 0 3} & 0.998 & 498.1 & 21.7 & 60\end{array}$


Supplementary Table 6 Pearson correlations between potential environmental drivers inside versus outside of protected areas, and partial Pearson correlations showing the relationship between these two variables once the effects of reserve area were removed statistically. $P$ values in bold have a Bonferroni-corrected value of $P \leq 0.0071$.

$\begin{array}{lcccr}\text { Driver } & \boldsymbol{R} & \boldsymbol{P} & \mathbf{n} & \text { Partial } \boldsymbol{R} \\ \text { Livestock grazing } & -0.1722 & 0.20 & 57 & -0.1643 \\ \text { Exotic-tree plantations } & -0.0274 & 0.84 & 56 & -0.0069 \\ \text { Selective logging } & 0.2300 & 0.0825 & 58 & 0.2123 \\ \text { Soil erosion } & 0.2401 & 0.0803 & 54 & 0.2418 \\ \text { Road expansion } & 0.2749 & 0.0351 & 59 & 0.2814 \\ \text { Population growth } & 0.2896 & 0.0261 & 59 & 0.3002 \\ \text { Natural forest cover } & 0.3232 & 0.0125 & 59 & 0.3340 \\ \text { Automobile traffic } & 0.3445 & 0.0081 & 58 & 0.3529 \\ \text { Fires } & 0.3623 & \mathbf{0 . 0 0 5 2} & 58 & 0.3518 \\ \text { NTFP harvests } & 0.3707 & \mathbf{0 . 0 0 6 3} & 53 & 0.3707 \\ \text { Illegal mining } & 0.4224 & \mathbf{0 . 0 0 1 2} & 56 & 0.4351 \\ \text { River \& stream flows } & 0.4355 & \mathbf{0 . 0 0 0 9} & 55 & 0.4321 \\ \text { Hunting } & 0.4381 & \mathbf{0 . 0 0 0 6} & 58 & 0.4314 \\ \text { Stream sedimentation } & 0.4615 & \mathbf{0 . 0 0 1} & 48 & 0.4608 \\ \text { Water pollution } & 0.4978 & \mathbf{0 . 0 0 0 1} & 57 & 0.5145 \\ \text { Air pollution } & 0.5874 & <\mathbf{0 . 0 0 0 1} & 54 & 0.5851 \\ \text { Drought severity/intensity } & 0.6374 & <\mathbf{0 . 0 0 0 1} & 50 & 0.6374 \\ \text { Flooding } & 0.6833 & <\mathbf{0 . 0 0 0 1} & 54 & 0.6995 \\ \text { Windstorm disturbance } & 0.7667 & <\mathbf{0 . 0 0 0 1} & 47 & 0.7474 \\ \text { Rainfall } & 0.7979 & <\mathbf{0 . 0 0 0 1} & 52 & 0.8060 \\ \text { Ambient temperature } & 0.8547 & <\mathbf{0 . 0 0 0 1} & 48 & 0.8496\end{array}$


Appendix 1 A non-interactive version of the 10-page interview form used in this study. The present study focuses on changes in the abundance of guilds, as well as the potential drivers of environmental change in our network of protected areas. Data on changes in species richness and composition of guilds are not included in the present analysis, because our experts generally had lower confidence in these trends.

\section{EXPERT QUESTIONNAIRE ON ENVIRONMENTAL CHANGES AT TROPICAL RESEARCH SITES}

\section{Objectives}

This is the first-ever effort to systematically assess environmental changes across a large and representative cross-section of the world's tropical protected areas and research sites. This survey is being based on a detailed assessment of expert opinion, using a standardized questionnaire.

The goals of the study are to determine the degree to which environmental changes and their drivers vary across different sites, and the degree to which they are similar. This study is also designed to assess whether tropical scientists are experiencing a "shifting baseline" because their study areas and their biota are changing in subtle or insidious ways.

The data being collected are qualitative and comparative in nature, and thus will not compromise in any way the ability of any investigator to publish his or her research findings about a particular research site.

This study is being led by Dr William Laurance of the Smithsonian Tropical Research Institute in Panama, with the assistance of Margareta Kalka and Julio Rendeiro. All individuals who provide detailed responses to this questionnaire as well as intellectual input on the manuscript will be offered coauthorship on at least one publication resulting from this work. Individuals who are especially helpful will be higher in the authorship list.

A critical assumption of expert questionnaires such as this is that the data being collected are reliable. Therefore, please do not respond to any question unless you have at least moderately good, direct or indirect knowledge of the issue at hand.

\section{Expert information}

(1) Full name

(2) Education level

(3) Field of expertise

(4) Gender

(5) Nationality

(6) Work address

(7) Email

(8) Phone

(9) First year of research at site

(10) Is your knowledge of the site

(11) Please rate your overall knowledge of the site

(12) How long has it been since you visited the site? months

Protected Area Information

(13) Complete name of Protected Area (PA)

(14) Longitude dd Latitude dd of PA

(15) Size of PA ha

(16) Name of Research Station within PA 
Expert Questionnaire on Environmental Changes at 'Rropical Research Sites

(17) Does the Focal Research Area (FRA) encompass the PA? -

If answered Yes, please skip to Question 23

If answered No, continue to Question 18

(18) Please describe the specific locality of the FRA within the PA (i.e. ne, nw, sw, se, center)

(19) What is the closest distance from the FRA to the border of the PA? km

(20) Size of FRA ha

(21) Elevation Range of FRA m

(22) Please identify your geographical FRA within the PA

(23) Does the $3 \mathrm{~km}$ area bordering the FRA lie mostly within a protected area? -

(24) Is the fragmentation of the FRA

(25) Within a $3 \mathrm{~km}$ radius, is the FRA -

(26) Please describe area surrounding the PA (land use, disturbance, human settlement, etc)

(27) How is protection enforced within the PA?

(28) What is the protection status of the FRA?

(29) How has the level of protection changed during your time associated with the FRA

(30) Please comment

Part 1: Changes in Animal and Plant Communities

FEEL FREE TO SKIP QUESTIONS FOR WHICH YOU HAVE LITTLE OR NO KNOWLEDGE.

FOR EACH QUESTION TO WHICH YOU RESPOND, PLEASE PROVIDE DETAILS OF CHANGE, AND FEEL FREE TO ELABORATE ABOUT THE KNOWN OR POSSIBLE DRIVERS OF THE CHANGE.

Over the past 2-3 decades, have any of the following groups changed in (1) Overall Abundance (A) or (2) Species Richness (SR) (native species only) at your FRA (within the PA)?

MAMMALS

(31) Top mammalian predators (e.g. jaguars, pumas, tigers, giant otters)

\begin{tabular}{ll|}
\hline Abundance & Species Richness \\
Please specify any above mentioned changes \\
Possible drivers of changes
\end{tabular}

(32) Large, non-predatory species (e.g. forest elephants, tapirs)

\begin{tabular}{lll|}
\hline Abundance & Species Richness \\
Please specify any above mentioned changes \\
Possible drivers of changes
\end{tabular}

(33) Primates

Abundance Species Richness Knowledge Level

Please specify any above mentioned changes

Possible drivers of changes 
Expert Questionnaire on Environmental Changes at Bropical Research Sites

(34) Omnivorous/opportunistic mammals

(e.g. bearded pigs, peccaries, opossums, coati mundis, all $>1 \mathrm{~kg}$ in weight)

Abundance Species Richness Knowledge Level

Please specify any above mentioned changes

Possible drivers of changes

(35) Rodents ( $<1 \mathrm{~kg}$ in weight)

\begin{tabular}{|ll|}
\hline Abundance & Knecies Richness \\
Please specify any above mentioned changes \\
Possible drivers of changes
\end{tabular}

(36) Bats

\begin{tabular}{|ll|}
\hline Abundance & \multicolumn{1}{c|}{ Species Richness } \\
Please specify any above mentioned changes \\
Possible drivers of changes
\end{tabular}

(38) Larger game birds (e.g. cracids, guans, curassows, pheasants)

\begin{tabular}{lll|}
\hline Abundance & Species Richness \\
Please specify any above mentioned changes \\
Possible drivers of changes
\end{tabular}

(39) Larger frugivorous birds (e.g. toucans, hornbills)

Species Richness

-

Please specify any above mentioned changes

Possible drivers of changes

(40) Raptors (e.g. eagles, hawks, falcons, owls)

\begin{tabular}{ll|}
\hline Abundance & Knowledge Level \\
\hline $\begin{array}{l}\text { Please specify any above mentioned changes } \\
\text { Possible drivers of changes }\end{array}$ & \\
\hline
\end{tabular}

AMPHIBIANS AND REPTILES

(41) Stream-dwelling amphibians

\begin{tabular}{|ll|}
\hline Abundance & Knecies Richness \\
\hline $\begin{array}{l}\text { Please specify any above mentioned changes Level } \\
\text { Possible drivers of changes }\end{array}$
\end{tabular}


Expert Questionnaire on Environmental Changes at Tropical Research Sites (42) Terrestrial amphibians

\begin{tabular}{|ll|}
\hline Abundance & Species Richness \\
\hline $\begin{array}{l}\text { Please specify any above mentioned changes } \\
\text { Possible drivers of changes }\end{array}$
\end{tabular}

(43) Lizards and larger reptiles

\begin{tabular}{ll|}
\hline Abundance & Knecies Richness \\
Please specify any above mentioned changes \\
Possible drivers of changes
\end{tabular}

\begin{tabular}{l} 
(44) Venomous snakes \\
\begin{tabular}{lll|} 
Abundance & Species Richness \\
Please specify any above mentioned changes \\
Possible drivers of changes
\end{tabular} \\
\hline
\end{tabular}

(45) Non-venomous snakes

\begin{tabular}{|ll|}
\hline Abundance & Species Richness \\
\hline $\begin{array}{l}\text { Please specify any above mentioned changes } \\
\text { Possible drivers of changes }\end{array}$ & \\
\hline
\end{tabular}

TERRESTRIAL INVERTEBRATES

(46) Light-loving butterflies

\begin{tabular}{ll|}
\hline Abundance & Species Richness \\
\hline $\begin{array}{l}\text { Please specify any above mentioned changes } \\
\text { Possible drivers of changes }\end{array}$ & \\
\hline
\end{tabular}

(47) Army ants (driver ants)

\begin{tabular}{|ll|}
\hline Abundance & Species Richness \\
\hline $\begin{array}{l}\text { Please specify any above mentioned changes } \\
\text { Possible drivers of changes }\end{array}$ & \\
\hline
\end{tabular}

(48) Leaf-cutter ants (Neotropics only)

\begin{tabular}{|l|l|}
\hline Abundance & Knecies Richness \\
Please specify any above mentioned changes \\
Possible drivers of changes
\end{tabular}

\begin{tabular}{l} 
(49) Dung beetles \\
\hline Abundance \\
\hline $\begin{array}{l}\text { Please specify any above mentioned changes } \\
\text { Possible drivers of changes }\end{array}$ \\
\hline
\end{tabular}

(50) Disease-vectoring invertebrates (e.g. mosquitoes, sandflies, ticks)
Abundance
Species Richness
Knowledge Level 
Expert Questionnaire on Environmental Changes at Bropical Research Sites

Please specify any above mentioned changes

Possible drivers of changes

\begin{tabular}{l} 
(51) Other group \\
\begin{tabular}{|l|l|} 
Abundance & Species Richness \\
Please specify any above mentioned changes \\
Possible drivers of changes
\end{tabular} \\
\hline
\end{tabular}

AQUATIC SPECIES

(52) Stream-fish assemblages

\begin{tabular}{|ll|}
\hline Abundance & Knowledge Level \\
\hline $\begin{array}{l}\text { Please specify any above mentioned changes } \\
\text { Possible drivers of changes }\end{array}$ & \\
\hline
\end{tabular}

(53) Aquatic invertebrates

\begin{tabular}{|ll|}
\hline Abundance & Species Richness \\
Please specify any above mentioned changes \\
Possible drivers of changes
\end{tabular}

PLANTS

(54) Large-seeded species, as a subset of climax species (e.g. many shade-tolerant trees)

\begin{tabular}{|l|l|}
\hline Abundance & Species Richness \\
\hline Please specify any above mentioned changes \\
Possible drivers of changes
\end{tabular}

(55) Pioneer species

\begin{tabular}{|ll|}
\hline Abundance & Knecies Richness \\
\hline $\begin{array}{l}\text { Please specify any above mentioned changes } \\
\text { Possible drivers of changes }\end{array}$ & \\
\hline
\end{tabular}

(56) Lianas/Climbing vines (predominantly light-loving)

\begin{tabular}{ll|}
\hline Abundance & Knowledge Level \\
Please specify any above mentioned changes \\
Possible drivers of changes
\end{tabular}

(57) Epiphytic plants (e.g. many orchids, bromeliads, ferns)

\begin{tabular}{ll|}
\hline Abundance & Knecies Richness \\
\hline $\begin{array}{l}\text { Please specify any above mentioned changes } \\
\text { Possible drivers of changes }\end{array}$ & \\
\hline
\end{tabular}

(58) Other group

Abundance $\quad$ Species Richness $\quad$ Knowledge Level


Expert Questionnaire on Environmental Changes at Tropical Research Sites

Please specify any above mentioned changes

Possible drivers of changes

GENERAL GROUPS

(59) Migratory species (e.g. bird and mammal frugivores or nectarivores, migratory fish)

Abundance Species Richness Knowledge Level

Please specify any above mentioned changes

Possible drivers of changes

(60) Ecological specialists (e.g. foraging specialists, species with complex mutualisms)

\begin{tabular}{ll|}
\hline Abundance & Species Richness \\
\hline Please specify any above mentioned changes \\
Possible drivers of changes
\end{tabular}

(61) Species dependent on tree cavities (parrots, certain possums, bats,...)

\begin{tabular}{|ll|}
\hline Abundance & Species Richness \\
\hline Please specify any above mentioned changes \\
Possible drivers of changes
\end{tabular}

(62) Exotic animal species (not native to FRA habitat)

\begin{tabular}{|ll|}
\hline Abundance & Knecies Richness \\
\hline $\begin{array}{l}\text { Please specify any above mentioned changes } \\
\text { Possible drivers of changes }\end{array}$ & \\
\hline
\end{tabular}

(63) Exotic plant species (not native to FRA habitat)

\begin{tabular}{|ll|}
\hline Abundance & Knecies Richness \\
\hline Please specify any above mentioned changes \\
Possible drivers of changes
\end{tabular}

(64) Human diseases (e.g. malaria, leishmaniasis, dengue fever, Chagas)

\begin{tabular}{lll|}
\hline Abundance & Knowledge Level \\
Please specify any above mentioned changes & \\
Possible drivers of changes & \\
\hline
\end{tabular}

\section{Part 2: Other Ecological/Anthropogenic Changes}

Over the past 2-3 decades, have any of the following changes occurred

(a) within the focal research area (FRA),

(b) in the $3 \mathrm{~km}$ area bordering the FRA, and

(c) in the general area outside the protected area (PA)

(65) For the area outside the PA, please approximate distance $(\mathrm{km})$ from border of PA

(66) Natural forest cover

\begin{tabular}{lllll}
\hline Within FRA & Within 3km of FRA & Within area outside PA & Knowledge level Likely impact on research \\
Details and possible drivers & & & \\
\hline
\end{tabular}


Expert Questionnaire on Environmental Changes at Tropical Research Sites

\begin{tabular}{|llll|}
\hline Within FRA & Wunting \\
\hline Details and possible drivers & & & \\
\hline
\end{tabular}

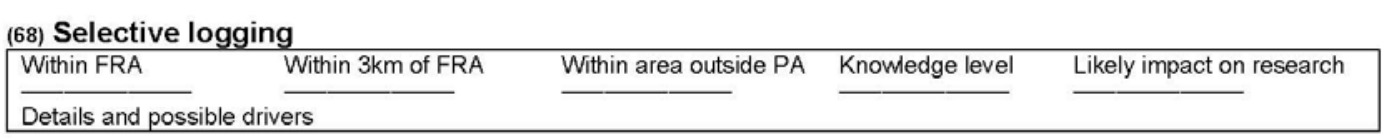

(69) Fires

\begin{tabular}{|llll|}
\hline Within FRA & Within 3km of FRA Within area outside PA Knowledge level & Likely impact on research \\
\hline Details and possible drivers & & \\
\hline
\end{tabular}

\begin{tabular}{|llll|}
\hline (70) Air pollution & & \\
\hline Within FRA & Within 3km of FRA & Within area outside PA & Knowledge level L Likely impact on research \\
\hline Details and possible drivers & & \\
\hline
\end{tabular}

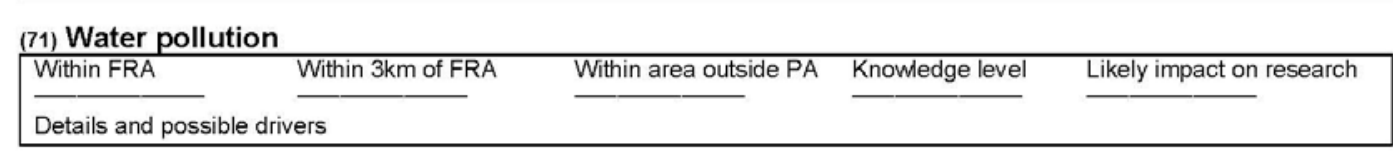

(72) Pastoralism/livestock grazing

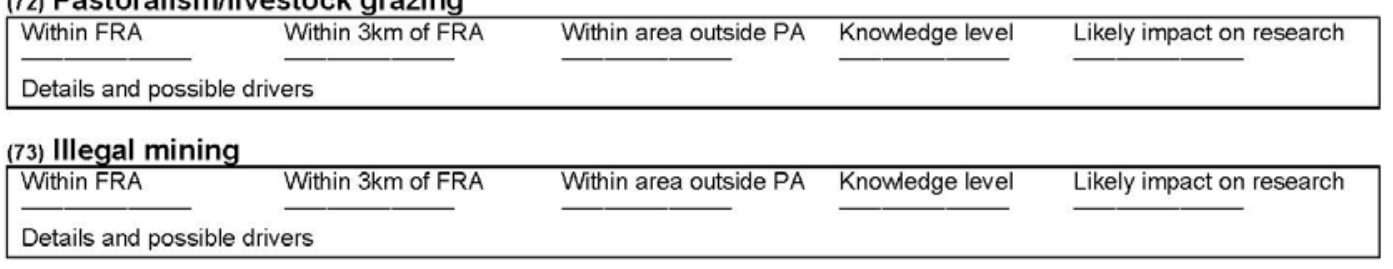

(74) Automobile traffic

\begin{tabular}{|llll|}
\hline Within FRA & Within 3km of FRA Within area outside PA Knowedge level & Likely impact on research \\
Details and possible drivers & & \\
\hline
\end{tabular}

(75) Harvest of natural products (e.g. fuelwood, tree bark, leaves, fungi, etc.)

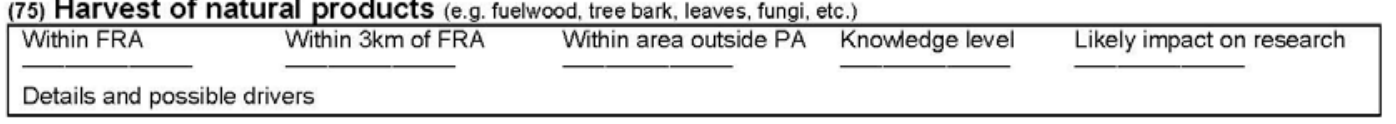

(76) Exotic tree plantations

\begin{tabular}{|llll|}
\hline Within FRA & Within 3km of FRA & Within area outside PA Knowedge level & Likely impact on research \\
\hline Details and possible drivers & &
\end{tabular}

(77) River/stream flows (e.g. from upstream dams or water harvesting)

\begin{tabular}{llll|}
\hline Within FRA & Within 3km of FRA Within area outside PA Knowedge level & Likely impact on research \\
\hline Details and possible drivers & &
\end{tabular}

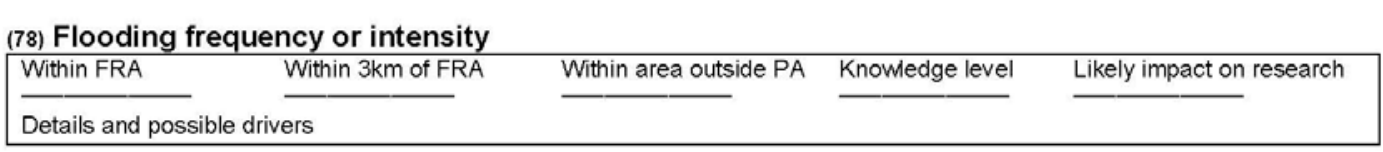

(79) Stream/river sedimentation 
Expert Questionnaire on Environmental Changes at Bropical Research Sites

\begin{tabular}{llll}
\hline Within FRA & Within 3km of FRA Within area outside PA Knowedge level & Likely impact on research \\
Details and possible drivers & &
\end{tabular}

\section{(80) Soil erosion}

\begin{tabular}{|lllll}
\hline Within FRA & Within 3km of FRA & Within area outside PA & Knowedge level Likely impact on research \\
Details and possible drivers & & &
\end{tabular}

(81) Windstorm disturbance

$\begin{array}{lllll}\text { Within FRA } & \text { Within 3km of FRA } & \text { Within area outside PA } & \text { Knowedge level Likely impact on research } \\ \text { Details and possible drivers } & & \end{array}$

(82) Drought

$\begin{array}{lllll}\text { Within FRA } & \text { Within } 3 \mathrm{~km} \text { of FRA } & \text { Within area outside PA } & \text { Knowledge level } & \text { Likely impact on research } \\ \text { Details and possible drivers } & & \end{array}$

(83) Rainfall

$\begin{array}{lllll}\text { Within FRA } & \text { Within 3km of FRA } & \text { Within area outside PA } & \text { Knowledge level Likely impact on research } \\ \text { Details and possible drivers } & & \end{array}$

(84) Temperature

\begin{tabular}{lllll}
\hline Within FRA & Within 3km of FRA & Within area outside PA Knowedge level Likely impact on research & \\
Details and possible drivers & &
\end{tabular}

(85) Forest dynamics, i.e. tree mortality and recruitment (accelerated/decelerated)

$\begin{array}{llll}\text { Within FRA } & \text { Within 3km of FRA Within area outside PA Knowledge level Likely impact on research } \\ \text { Details and possible drivers } & \end{array}$

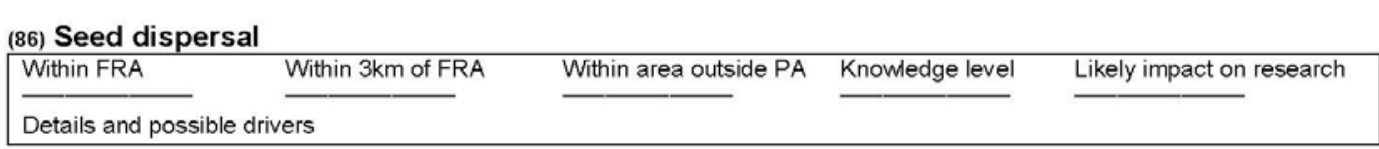

(87) Seedling predation

\begin{tabular}{|llll}
\hline Within FRA & Within 3km of FRA & Within area outside PA Knowledge level Likely impact on research & \\
Details and possible drivers & & & \\
\hline
\end{tabular}

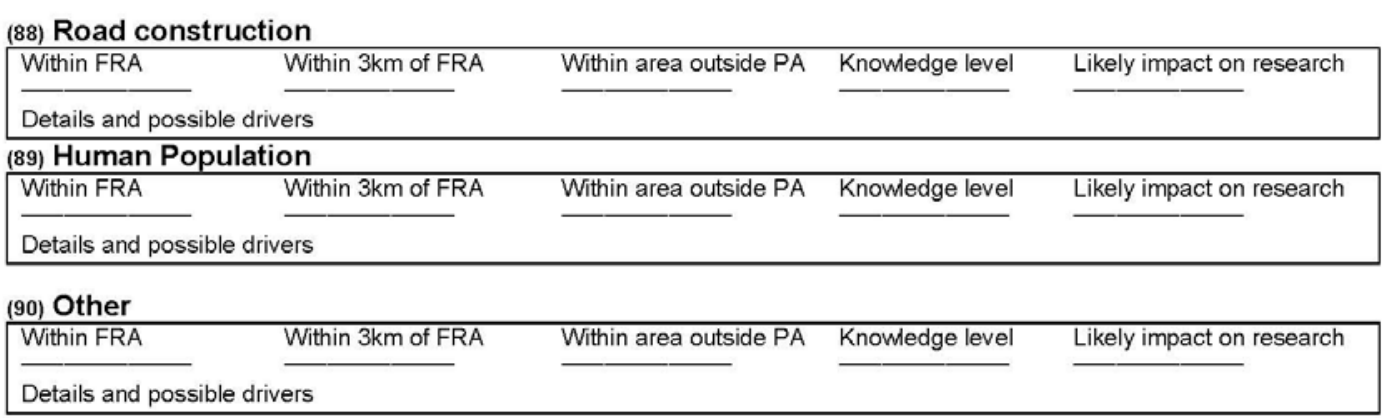

\section{Part 3: Additional Questions}


Expert Questionnaire on Environmental Changes at Dropical Research Sites

What do you think will be the biggest future threats to your site, and could you identify possible solutions?

(91) First biggest threat

Possible solution

(92) Second biggest threat

Possible solution

(93) Third biggest threat

Possible solution

(94) Can you recommend other experts on this site?

(95) Expert 1

\begin{tabular}{|c|c|c|}
\hline Name & Expertise & Email \\
\hline \multicolumn{3}{|c|}{ (96) Expert 2} \\
\hline Name & Expertise & Email \\
\hline \multicolumn{3}{|c|}{ (97) Expert 3} \\
\hline Name & Expertise & Email \\
\hline \multicolumn{3}{|c|}{ (98) Expert 4} \\
\hline Name & Expertise & Email \\
\hline \multicolumn{3}{|c|}{ (99) Expert 5} \\
\hline Name & Expertise & Email \\
\hline \multicolumn{3}{|c|}{ (100) Expert 6} \\
\hline Name & Expertise & Email \\
\hline \multicolumn{3}{|c|}{ (101) Expert 7} \\
\hline Name & Expertise & Email \\
\hline \multicolumn{3}{|c|}{ (102) Expert 8} \\
\hline Name & Expertise & Email \\
\hline
\end{tabular}

(103) Do you have knowledge of long-term changes of other tropical research sites, and if so, would you be willing to be interviewed about them for our survey?

(104) Site1

Name Country

(105) Site 2

Name Country

(106) Site 3

\begin{tabular}{|lc|}
\hline Name Country \\
\hline
\end{tabular}

(107) Would you be interested in remaining further involved with this study and in co-authorship of a resulting publication?

(108) Comment

Please provide publications describing environmental changes at this site.

(109) Publication 1

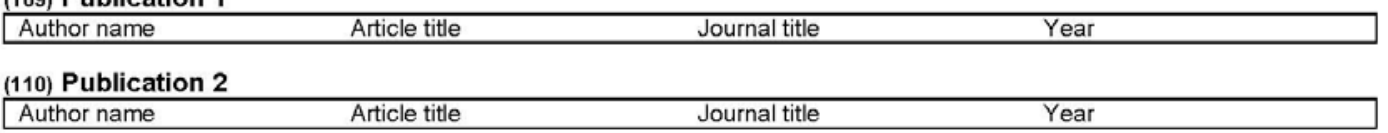


Expert Questionnaire on Environmental Changes at IItropical Research Sites (111) Publication 3

Author name

Article title
Journal title

Year

(112) Comment

Thank you very much for your time and we greatly appreciate your participation in this study. 